Article

\title{
A MODIS-Based Novel Method to Distinguish Surface Cyanobacterial Scums and Aquatic Macrophytes in Lake Taihu
}

\author{
Qichun Liang ${ }^{1,2}$, Yuchao Zhang ${ }^{1,3, *}$, Ronghua Ma ${ }^{1,3}$, Steven Loiselle ${ }^{4}$, Jing $\mathrm{Li}^{1,2}$ and \\ Minqi $\mathrm{Hu}^{1,2}$ \\ 1 Key Laboratory of Watershed Geographic Sciences, Nanjing Institute of Geography and Limnology, \\ Chinese Academy of Sciences, Nanjing 210008, China; lqc_niglas@163.com (Q.L.); rhma@niglas.ac.cn (R.M.); \\ crystalleegis@163.com (J.L.); huminqi16@mails.ucas.ac.cn (M.H.) \\ 2 University of Chinese Academy of Sciences, Beijing 100049, China \\ 3 Jiangsu Collaborative Innovation Center of Regional Modern Agriculture \& Environmental Protection, \\ Huaiyin Normal University, Huai'an 223300, China \\ 4 Dipartimento di Biotecnologie, Chimica e Farmacia, University of Siena, CSGI, Via Aldo Moro 2, Siena 53100, \\ Italy; loiselle@unisi.it \\ * Correspondence: yczhang@niglas.ac.cn; Tel.: +86-25-8688-2165
}

Academic Editors: Yunlin Zhang, Claudia Giardino, Linhai Li, Deepak R. Mishra, Richard Gloaguen and Prasad S. Thenkabail

Received: 30 August 2016; Accepted: 26 January 2017; Published: 6 February 2017

\begin{abstract}
Satellite remote sensing can be an effective alternative for mapping cyanobacterial scums and aquatic macrophyte distribution over large areas compared with traditional ship's site-specific samplings. However, similar optical spectra characteristics between aquatic macrophytes and cyanobacterial scums in red and near infrared (NIR) wavebands create a barrier to their discrimination when they co-occur. We developed a new cyanobacteria and macrophytes index (CMI) based on a blue, a green, and a shortwave infrared band to separate waters with cyanobacterial scums from those dominated by aquatic macrophytes, and a turbid water index (TWI) to avoid interference from high turbid waters typical of shallow lakes. Combining CMI, TWI, and the floating algae index (FAI), we used a novel classification approach to discriminate lake water, cyanobacteria blooms, submerged macrophytes, and emergent/floating macrophytes using MODIS imagery in the large shallow and eutrophic Lake Taihu (China). Thresholds for CMI, TWI, and FAI were determined by statistical analysis for a 2010-2016 MODIS Aqua time series. We validated the accuracy of our approach by in situ reflectance spectra, field investigations and high spatial resolution HJ-CCD data. The overall classification accuracy was $86 \%$ in total, and the user's accuracy was $88 \%, 79 \%, 85 \%$, and $93 \%$ for submerged macrophytes, emergent/floating macrophytes, cyanobacterial scums and lake water, respectively. The estimated aquatic macrophyte distributions gave consistent results with that based on HJ-CCD data. This new approach allows for the coincident determination of the distributions of cyanobacteria blooms and aquatic macrophytes in eutrophic shallow lakes. We also discuss the utility of the approach with respect to masking clouds, black waters, and atmospheric effects, and its mixed-pixel effects.
\end{abstract}

Keywords: Cyanobacteria and macrophytes index; Floating algae index; Cyanobacteria blooms; aquatic macrophytes; Lake Taihu; MODIS

\section{Introduction}

Cyanobacteria dominated blooms are ubiquitous in many freshwater ecosystems affected by human activities, increasing in frequency and distribution since the 1940s [1,2]. These blooms have 
multiple adverse impacts on local environments and economy, with a classic example being the extensive and long-lasting bloom in Lake Taihu in 2007 [3].

Aquatic macrophytes support critical ecological services in most shallow lakes by providing the habitat for a diverse and economically important faunal community, sequestering carbon and nutrients, as well as stabilizing sediment and shorelines [4-6]. Many studies indicate that eutrophication may lead to a reduction in macrophyte coverage as competition for available light and nutrients is impacted by an increase in phytoplankton, suspended detritus and periphyton [7]. Macrophyte coverage can indicate catchment scale and lake scale impacts of climate change on storm frequency, lake temperature, and sediment inflow [8]. The distributional changes in the coverage of aquatic vegetation and cyanobacterial scums can be considered an indicator of lake ecosystem conditions. The availability of accurate long-term information of the distribution of cyanobacterial scums and aquatic macrophytes can be a fundamental tool to lake management.

In reality, in situ measurements are often inappropriate to deal with the complex temporal and spatial dynamics of cyanobacterial scums, due to rapid vertical migration [9] and very fast replication [10], while the study of aquatic macrophytes requires a seasonal approach. In recent decades, remote sensing became a fundamental tool to explore the spatial and temporal behavior of aquatic ecosystems. Many studies have successfully used optical remote sensing to map algal blooms [11-13] and aquatic macrophytes [14-16] in coastal, lacustrine, and lagoon environments.

Remote sensing of cyanobacterial scums includes indirect approaches using water quality parameters such as transparency and direct approaches based on photosynthetic pigments concentrations (chlorophyll-a and phycocyanobilin) and spectrum shape characteristics (Table 1) [17]. These chlorophyll-a algorithms become problematic in the event of surface scums, where thick foams and complex chemical constituents are present [18], and have led to the development of new qualitative approaches. Algorithms using near infra-red (NIR) bands have shown particular promise, based on the red-edge effect to vegetation of blooms [18] including single band [19-22], band ratio [23-29] and band difference [30,31], and some land vegetation indices such as Normalized Difference Vegetation Index [25,32-35] and Enhanced Vegetation Index [25,36]. NIR bands are also the basis for spectral shape methods, which use a computational equivalent to the second derivative [37], including Fluorescent Line Height [38], Maximum Chlorophyll Index [39], Spectral Shape index [40-42], Cyanobacterial Index [37,43], Maximum Peak-Height algorithm [44,45], Floating Algae Index [46-50], and a Classification And Regression Tree [51].

Methods for identifying aquatic macrophytes by remote sensing have also undergone important developments (Table 2), including unsupervised classifier [52-57], supervised classifier [58,59], classification trees [60-67] and remote sensing combined with ancillary data [68,69]. Ratios of band reflectances or band transformations (e.g., normalized difference index) based on the spectral characteristics of macrophytes in the visible and NIR wavelengths can be used for macrophyte detection and classification.

Due to their similar spectral characteristics, especially in red and NIR wavelengths, it is often difficult to distinguish cyanobacterial scums and aquatic macrophytes by remote sensing. According to Gao's [70] and Rogers and Kearney's [71] results that short-wave infrared (SWIR) bands were sensitive to vegetation liquid water, Oyama [67] used SWIR bands of Landsat TM for distinguishing cyanobacterial scums and aquatic macrophytes, with the floating algae index (FAI) and normalized difference water index (NDWI) in Japanese lakes. However, extremely thick cyanobacterial surface scums in Lake Taihu with relatively sparse aquatic macrophytes present a more complex condition. Furthermore, SWIR is sensitive to conditions of elevated turbidity, a common characteristic of most shallow lakes. The approach combined vegetation presence frequency (VPF) and FAI, suggested by Liu [68], suffered from similar challenges from highly turbid or highly absorbing "black" waters. Otherwise, this VPF method could not be utilized for routine monitoring because it is one of the retrospective evaluation approaches. 
Compared to Landsat TM/ETM+, MERIS, and MODIS imagery provide advantages for large lakes due to their short overpass period and good spatial resolution [72,73]. MERIS, accessible until April 2012, provided important insights into the concentrations of optically active substances in large lakes [45,74]. MODIS (1999-present for Terra, 2002-present for Aqua) provides frequent (daily) and synoptic global observations and is equipped with several medium-resolution bands ("sharpening" bands designed for land use), and is also the prototype for VIIRS (the Visible Infrared Imager/Radiometer Suite) [75,76], allowing MODIS algorithms to inform algorithm development for VIIRS.

In the present study, we develop and validate a new approach to distinguish lake water, cyanobacterial scums and different aquatic macrophytes in complex aquatic and atmospheric optical conditions and mixed-pixel effects.

Table 1. Remote sensing identification methods on algal blooms in lakes and coastal sea with satellite data.

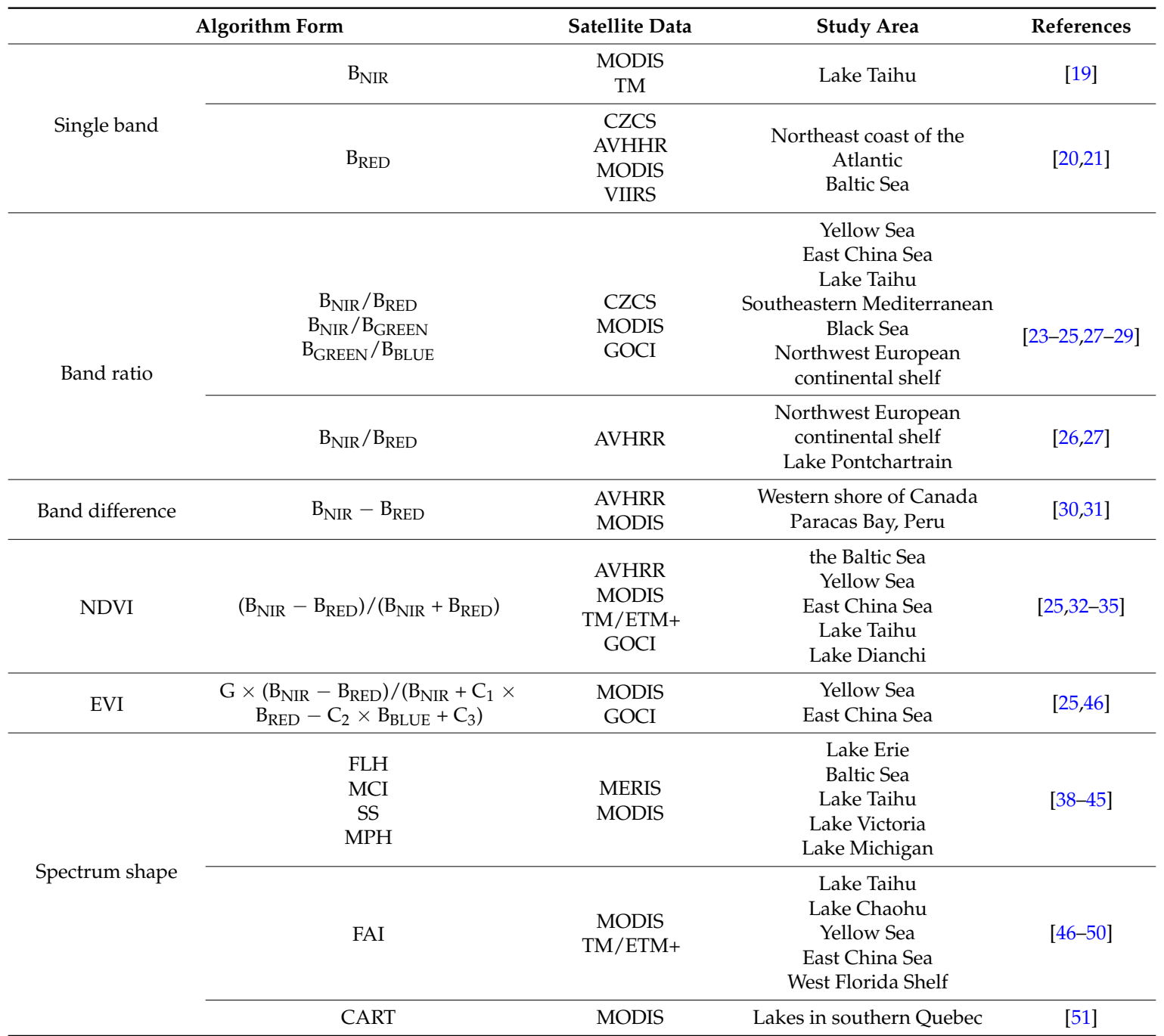

NDVI: Normalized Difference Vegetation Index; EVI: Enhanced Vegetation Index; FLH: Fluorescent Line Height; MCI: Maximum Chlorophyll Index; SS: Spectral Shape index; MPH: Maximum Peak-Height algorithm; FAI: Floating Algae Index; CART: Classification and Regression Tree. 
Table 2. Aquatic macrophytes mapping approaches by satellite data.

\begin{tabular}{cccc}
\hline Approaches & Satellite Data & Study Area & References \\
\hline Unsupervised classifier & $\begin{array}{c}\text { Landsat-1 } \\
\text { TM/ETM+ } \\
\text { IRS-1B LISS-II Quickbird }\end{array}$ & $\begin{array}{c}\text { North Dakota } \\
\text { California's Central Valley } \\
\text { Great Bay, New Hampshire } \\
\text { Grand Teton National Park, USA } \\
\text { Lake Mogan Chwaka Bay }\end{array}$ & [52-57] \\
\hline Supervised classifier & TM/ETM+ & $\begin{array}{c}\text { Lower Mekong Basin } \\
\text { Yakima River }\end{array}$ & {$[58,59]$} \\
\hline Classification trees & TM/ETM+ & $\begin{array}{c}\text { DelawareWater Gap National Recreation Area } \\
\text { Gallatin Valley of Southwest Montana, USA } \\
\text { Yellowstone National Park } \\
\text { Camargue or Rhône delta } \\
\text { Lake Taihu } \\
\text { Japanese lakes }\end{array}$ & {$[60-67]$} \\
\hline Classification trees with \\
ancillary data
\end{tabular}

\section{Study Area and Data}

\subsection{Lake Taihu}

Lake Taihu, the third largest freshwater lake in China, is located in the Yangtze River Delta (latitude $30^{\circ} 55^{\prime} 40^{\prime \prime}-31^{\circ} 32^{\prime} 58^{\prime \prime} \mathrm{N}$; longitude $119^{\circ} 52^{\prime} 32^{\prime \prime}-120^{\circ} 36^{\prime} 10^{\prime \prime} \mathrm{E}$, Figure 1 ). The lake has a surface area of $2338 \mathrm{~km}^{2}$, a maximum and average depth of 2.6 and $1.9 \mathrm{~m}$, respectively, with a mean water residence time of approximately 309 days [77]. Due to the rapid economic growth through urbanization and industrialization of Lake Taihu basin, increasing eutrophication and recurrent cyanobacterial scums (Microcystis) have occurred in recent years, posing a significant threat to millions of people relying on the lake for drinking water supply [78]. Harmful cyanobacterial scums regularly occur in the northern Meiliang, Zhushan, and Gonghu bays and on the western lakeshore [19]. The eastern and southern lake areas are characterized by extensive areas of macrophytes, where turbidity is low and cyanobacterial scums are rare [68,79]. Thus many researchers always divided Lake Taihu into cyanobacteria-dominated zone and a macrophytes-dominated zone [64-66]. On the basis of havitat, aquatic macrophytes can always be subdivided as emergent, floating-leaved, and submerged macrophytes [80]. Fourteen dominant species of aquatic macrophytes were identified in historical surveys in Lake Taihu (Table 3), including two emergent species, three floating species and nine submerged species [81]. In recent field investigations between 2013-2016, submerged macrophytes (i.e., Potamogeton crispus) have re-appeared in areas where they have been absent for more than a decade, Zhushan and Meiliang Bays.

\subsection{Field Data}

Two hundred and sixty six in situ investigations were carried out in July and August of 2013, May of 2014, June of 2015, and May of 2016 (Figure 1), covering the whole lake. Of the investigations $82.7 \%$ were located in the bays, especially in the eastern lake, always covered with aquatic macrophytes or cyanobacterial scums. The name and classification (emergent, floating, and submerged macrophytes) of aquatic vegetation, GPS and photographs of each site were recorded, and the percentage coverage of the aquatic macrophytes were estimated by eye from the boat during field investigations. Otherwise, 37 in situ water leaving reflectance spectra $R_{r s}(\lambda)$ were measured in September of 2014 and April of 2015 . 


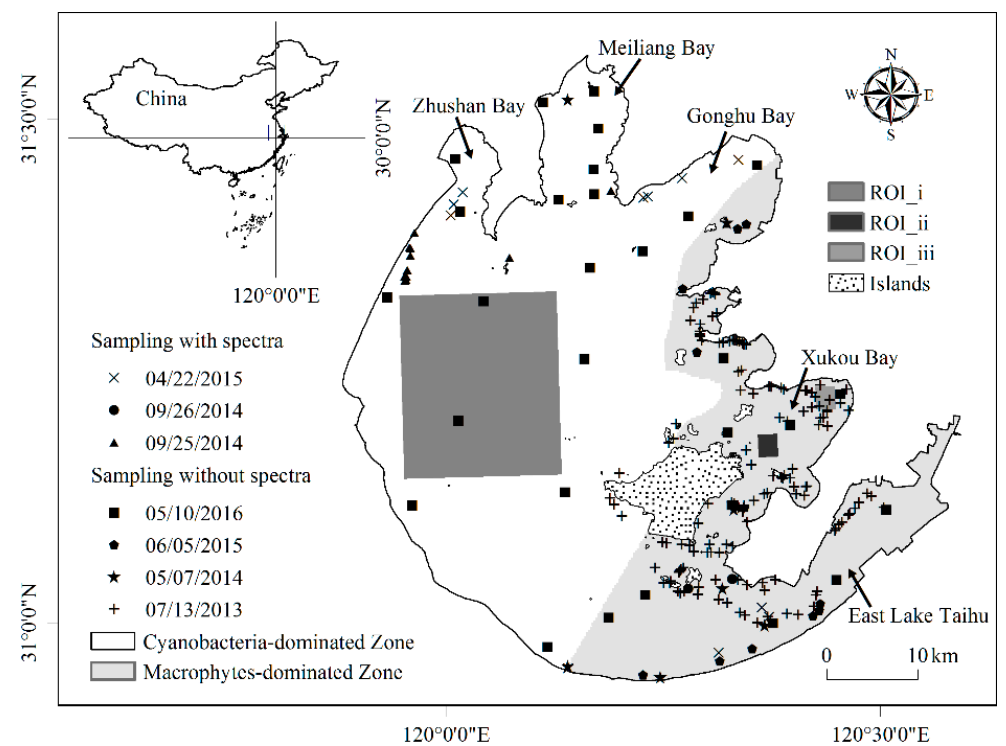

Figure 1. The locations of field investigation samples collected from 2013 to 2016.

Table 3. Main dominant aquatic macrophytes in Lake Taihu due to field investigation.

\begin{tabular}{|c|c|c|c|}
\hline Type & Havitat & Dominant Macrophyte & Max Height \\
\hline \multirow{2}{*}{$\begin{array}{c}\text { Emerged } \\
\text { macrophytes }\end{array}$} & \multirow{2}{*}{$\begin{array}{l}\text { Frequently growing above the waterline of lakes and } \\
\text { wetlands with only their roots located in wet or damp soils }\end{array}$} & Phragmites australis & $2-5 \mathrm{~m}$ \\
\hline & & Zizania latifolia & $1.6-2 \mathrm{~m}$ \\
\hline $\begin{array}{l}\text { Floating-leaved } \\
\text { macrophytes }\end{array}$ & $\begin{array}{l}\text { Having roots located into sediment and stems to lift the } \\
\text { leaves floating above the water surface }\end{array}$ & $\begin{array}{l}\text { Nymphoides peltatum; } \\
\text { Nymphoides indica; } \\
\text { Trapa maximowiczii; }\end{array}$ & $\begin{array}{l}\text { Above the } \\
\text { water surface }\end{array}$ \\
\hline \multirow[t]{3}{*}{$\begin{array}{l}\text { Submerged } \\
\text { macrophytes }\end{array}$} & \multirow[t]{3}{*}{$\begin{array}{l}\text { Being usually but not always rooted, and putting their } \\
\text { whole body under the water except flowers }\end{array}$} & $\begin{array}{l}\text { Potamogeton maackianus; } \\
\text { Potamogeton malaianus; } \\
\text { Ceratophyllum demersum; } \\
\text { Hydrilla verticillata; } \\
\text { Myriophyllum spicatum; } \\
\text { Elodea nuttalli; } \\
\text { Potamogeton crispus }\end{array}$ & $\begin{array}{l}\text { Under the } \\
\text { water surface }\end{array}$ \\
\hline & & Vallisneria natans & $-1.2 \mathrm{~m}$ \\
\hline & & Chara & $-0.5 \mathrm{~m}$ \\
\hline
\end{tabular}

We measured the $\mathrm{R}_{\mathrm{rs}}(\lambda)$ for two emergent macrophytes (Zizania caduciflora; Phragmites australis), one floating macrophytes (Nymphoides peltatum) and two submerged macrophytes (Potamogeton crispus; Potamogeton maackianus). In situ $\mathrm{R}_{\mathrm{rs}}(\lambda)$ were measured with a FieldSpec FR spectroradiometer (Analytical Spectral Devices, Boulder, CO) with the wavelength range from 350 to $2500 \mathrm{~nm}$ following the NASA Ocean Optics protocols [82]. As recommended by Mobley [83], a viewing geometry with an azimuth of $135^{\circ}$ and zenith of $40^{\circ}$, was used to avoid water surface reflection from direct sun. Each water spectrum was sampled $90^{\circ}$ azimuth with respect to the sun and with a viewing angle of $45^{\circ}$. The detector integration time was either $136 \mathrm{~ms}$ or $272 \mathrm{~ms}$. A separate dark reading was obtained each time the integration time was changed. The measurement sequence, repeated five times for each measurement, began with a measurement of a standard $25 \mathrm{~cm} \times 25 \mathrm{~cm}$ plaque ( $25 \%$ reflectivity), water and sky radiances (each preceded by a dark offset reading). The water surface reflectance factor $\rho$ was assumed to be 0.028 but clearly depended on sky conditions, wind speed, and solar zenith angle [83]. The viewing direction of $40^{\circ}$ and $135^{\circ}$ from the sun was considered a reasonable compromise. This method has been used successfully in sea and inland lakes studies in conditions where wind speeds less than $5 \mathrm{~m} / \mathrm{s}$ [83-86]. The viewing direction was set by adjusting the instrument angle to minimize the effects of sun glint and non-uniform sky radiance while also avoiding instrument shading. Measurements were made from a location that minimized shading, 
reflections from superstructure, ship's wake, associated foam patches and whitecaps, and specular reflection of sunlight.

\subsection{Satellite Image Data Processing}

MODIS Level-0 data collected by Aqua (2010-2016) covering the study region were obtained from the NASA Goddard Space Flight Center through its Ocean Biology Processing Group (OBPG) [87]. We used five bands from $469 \mathrm{~nm}$ to $1240 \mathrm{~nm}$ designed for land and atmosphere use, with a lower dynamic range than the ocean bands, and therefore unlikely to saturate in the highly turbid conditions of this shallow lake. The ground resolution of the 645 and $859 \mathrm{~nm}$ band is $250 \mathrm{~m}$, and $500 \mathrm{~m}$ for the bands at 469,555 , and $1240 \mathrm{~nm}$.

MODIS data were processed using SeaDAS (version 7.0). First, the data were converted to calibrated radiance (Level-1B). A key challenge remains in Case II waters, to perform a full atmospheric correction where significant errors in visible range occur for turbid waters with classic atmospheric correction methods, such as Gordon and Clark [88], Ruddick, Ovidio, and Rijkeboer [89], Wang and Shi [90], and Bailey, Franz, and Werdell [91] etc. Therefore, to avoid this problem, a partial atmospheric correction to correct for the gaseous absorption (mainly by ozone) and Rayleigh (molecular) scattering effects was applied to the Level-1B data, resulting in Rayleigh corrected reflectance (Rrc, dimensionless):

$$
R_{r c}(\lambda)=\rho_{t}(\lambda)-\rho_{r}(\lambda)=\rho_{a}(\lambda)+\pi \times t(\lambda) \times t_{0}(\lambda) \times R_{r s}(\lambda)
$$

where $\rho_{t}$ is the top of atmosphere (TOA) reflectance after adjustment of the atmospheric (gas) absorption, $\rho_{r}$ is the reflectance due to Rayleigh scattering, $\rho_{a}$ is the reflectance due to aerosol scattering and aerosol-Rayleigh interactions, $t$ and $t_{0}$ are diffuse transmittance from the image pixel to the satellite and from the sun to the image pixel, respectively. Note that $\rho_{a}, t$, and $t_{0}$ are functions of aerosol type, aerosol optical thickness, and solar/viewing geometry. The above formulation assumes negligible contributions from whitecaps and sun glint.

The Rrc data were mapped to a cylindrical equidistant projection for further analysis. First, the Rrc data at $645 \mathrm{~nm}, 555 \mathrm{~nm}$, and $469 \mathrm{~nm}$ were used to compose the Red-Green-Blue true color images to screen for clouds and sun glint. After visual inspection, a total of 176 data granules between 2010 and 2015 (Table 4) were found to contain no cloud cover and sun glint, therefore suitable for thresholds determination and method development.

Table 4. Temporal distribution of MODIS Aqua imageries used in this study.

\begin{tabular}{ccccccccc}
\hline & $\mathbf{2 0 1 0}$ & $\mathbf{2 0 1 1}$ & $\mathbf{2 0 1 2}$ & $\mathbf{2 0 1 3}$ & $\mathbf{2 0 1 4}$ & $\mathbf{2 0 1 5}$ & $\mathbf{2 0 1 6}$ & Total \\
\hline January & 0 & 0 & 2 & 0 & 5 & 5 & 5 & 17 \\
February & 0 & 0 & 0 & 0 & 0 & 5 & 13 & 18 \\
March & 1 & 0 & 2 & 4 & 10 & 2 & 5 & 24 \\
April & 0 & 2 & 1 & 7 & 0 & 3 & 4 & 17 \\
May & 4 & 1 & 5 & 6 & 4 & 2 & 3 & 25 \\
June & 1 & 1 & 0 & 0 & 0 & 2 & 2 & 6 \\
July & 1 & 3 & 3 & 2 & 1 & 2 & 2 & 14 \\
August & 4 & 0 & 0 & 5 & 0 & 5 & & 14 \\
September & 2 & 4 & 1 & 1 & 0 & 2 & & 10 \\
October & 1 & 2 & 5 & 3 & 6 & 5 & & 22 \\
November & 1 & 0 & 3 & 7 & 4 & 1 & & 16 \\
December & 6 & 0 & 0 & 2 & 14 & 5 & & 27 \\
Total & 21 & 13 & 22 & 37 & 44 & 39 & 34 & 210 \\
\hline
\end{tabular}

To further validate the results, we used the aquatic macrophyte distributions done by Luo [66] using HJ-CCD images. HJ-1A and HJ-1B satellites were launched by the China Center for Resources Satellite Data and Application (CRESDA) on September 2008, have a high revisit time (2 days) and 
wavebands (B1: 430-520; B2: 520-600; B3: 630-690; B4: 760-900 nm) that are appropriate for vegetation mapping. According to Luo's article [66], radiometric calibrations were made first using coefficients provided with the image (e.g., gains and offsets), then the atmospherically corrected images were geometrically corrected against a historical Landsat TM image with geometric accuracy of $<0.5$ pixel, and lastly the FLAASH module was applied for atmospheric correction. All of the lake except Gonghu Bay and the eastern lake was masked in Luo's research.

\section{Methods}

\subsection{Spectral Features of Lake Water, Cyanobacterial Scums, and Aquatic Macrophytes}

Spectra for clear lake water had the maximum reflectance at the wavelengths between $550-580 \mathrm{~nm}$ (Figure 2). Reflectance decreased sharply on both sides of the maximum, with reflectance at $500 \mathrm{~nm}$ higher than at $650 \mathrm{~nm}$ [92]. The reflectance spectra of turbid waters were typical, with a low reflectance in blue range and high reflectance in green range, owing to the absorption by dissolved organic matter and tripton as well as backscattering by particulate matter [93]. Reflectance in the red region $(600-700 \mathrm{~nm})$ had two minima around $620 \mathrm{~nm}$ and $675 \mathrm{~nm}$, associated to phycocyanobilin and chlorophyll-a absorption [94,95]. A distinct peak around $700 \mathrm{~nm}$ shifted from $690 \mathrm{~nm}$ at low chlorophyll-a concentrations to $715 \mathrm{~nm}$ at high chlorophyll-a concentrations, which resulted from both high backscattering and minimum absorption by all optically active constituents, including pure water [96]. For low chlorophyll-a and high suspended sediments, this peak was reduced. The scattering by all particulate matter controlled the variations of NIR reflectance [93].

The reflectance spectra of cyanobacterial scums not only had the typical chlorophyll-a and phycocyanobilin absorption at 442, 665, and $620 \mathrm{~nm}$ respectively, but also an increase in wavelengths ranging from 700 and $1800 \mathrm{~nm}$ with chlorophyll-a concentrations compared to that at visible and longer than $1900 \mathrm{~nm}$ range [67]. This is similar to reflectance spectra of aquatic macrophytes.
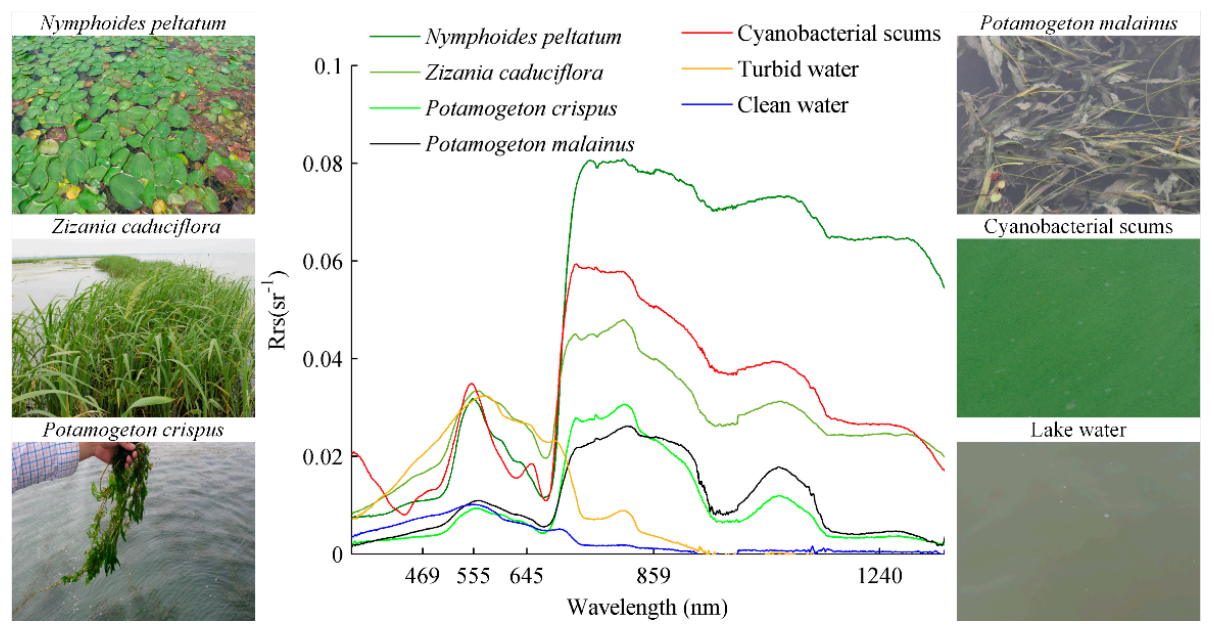

Figure 2. The in situ reflectance spectra and corresponding photographs of water, turbid water, cyanobacterial scums, and some typical aquatic macrophytes observed in Lake Taihu. Spectra were determined by the average spectra of each aquatic macrophytes.

For aquatic macrophytes, high reflectance values at the NIR region are mainly due to the cellular structure in the leaves [97]. A small absorption around $970 \mathrm{~nm}$ has been associated to water content [14], and is similar to that observed in the reflectance spectra of cyanobacterial scums [67]. All aquatic macrophytes investigated in Lake Taihu have similar reflectance spectra with pigment concentration and cellular structure responsible for observable differences [16]. Submerged macrophytes have lower reflectance values across the whole range due to the water absorption [16]. 


\subsection{A New Classification Method for MODIS}

\subsubsection{CMI, FAI, and TWI}

Considering the similar NIR reflectance spectra between cyanobacterial scums and aquatic macrophytes, indices based on other wavelengths were necessary to distinguish them. Compared to aquatic macrophytes, the Rrc spectra of cyanobacterial scums have a distinguishable peak at $555 \mathrm{~nm}$ and an obvious minimum at $469 \mathrm{~nm}$ (Figure 3). We note that the Rrc data used removed Rayleigh scattering effects but not aerosol or other atmospheric effects. The use of the $1240 \mathrm{~nm}$ band to construct a baseline with $469 \mathrm{~nm}$ removed additional impacts from atmospheric effects. This suggests that the difference between $\operatorname{Rrc}(555)$ and baseline between $469 \mathrm{~nm}$ and $1240 \mathrm{~nm}$, can be used to distinguish cyanobacterial scums and aquatic macrophytes. The resulting Cyanobacteria and Macrophytes Index (CMI) was defined as:

$$
C M I=R_{r c, G R E E N}-R_{r c, B L U E}-\left[R_{r c, S W I R}-R_{r c, B L U E}\right] \times\left(\lambda_{\text {GREEN }}-\lambda_{B L U E}\right) /\left(\lambda_{\text {SWIR }}-\lambda_{B L U E}\right)
$$

following a baseline subtraction similar to the FAI index [46] with clearly different band combinations. FAI, widely used for detecting floating algae in lakes [47,50] was expanded in this study to identify different types of aquatic macrophytes as well as floating algae. FAI was originally developed using MODIS red, NIR, and SWIR bands,

$$
F A I=R_{r c, N I R}-R_{r c, R E D}-\left[R_{r c, S W I R}-R_{r c, R E D}\right] \times\left(\lambda_{N I R}-\lambda_{R E D}\right) /\left(\lambda_{S W I R}-\lambda_{R E D}\right)
$$

When very high suspended sediments are present, they can dominate the optical signal, leading both CMI and FAI to identify areas of high turbidity as cyanobacterial scums. To avoid this, we created a Turbid Water Index (TWI), following algorithm approaches for suspended solids in Case II waters [98]:

$$
T W I=R_{r c, R E D}-R_{r c, S W I R}
$$

For MODIS, these are $\lambda_{B L U E}=469 \mathrm{~nm}, \lambda_{\text {GREEN }}=555 \mathrm{~nm}, \lambda_{R E D}=645 \mathrm{~nm}$, and $\lambda_{\text {SWIR }}=1240 \mathrm{~nm}$.

\subsubsection{Classification Tree}

The relationship between CMI, FAI, and NDWI [67] from typical lake waters (Figure 3) showed $\mathrm{CMI}_{\text {cyano }}>\mathrm{CMI}_{\text {water }}>\mathrm{CMI}_{\text {float }}>\mathrm{CMI}_{\text {sub }}$. While $\mathrm{CMI}$ of floating macrophytes was much lower than that of cyanobacterial scums, respective FAIs overlapped significantly. Likewise, the FAI of the open lake water and clean water with submerged macrophytes in Xukou Bay were similar. Due to Oyama's research, NDWI showed a much better capability to distinguish cyanobacterial scums and aquatic macrophytes using Landsat TM/ETM+ [67]. Figure 3b indicated that NDWI of cyanobacterial scums, aquatic macrophytes, and lake water mixed together based on MODIS data. The impact of high concentrations of suspended solids on water reflectance at green, red, and NIR range was evident, as was its impact on CMI and FAI in turbid waters.

A classification decision tree based on these relationships was constructed with five steps (Figure 4). Step 1: identify and remove pixels of turbid water by TWI; Step 2: chose the CMI and FAI thresholds due to the pixel location (cyanobacteria-dominated or macrophytes-dominated zone); Step 3: identify which is existing in the pixel, cyanobacterial scum or aquatic macrophytes by CMI threshold; Step 4: if cyanobacterial scum exists, identify lake waters using FAI $=-0.004$; Step 5: if aquatic macrophytes exists, distinguish between floating and emergent/submerged macrophytes using FAI threshold.

Three regions of interest (ROI_i, ROI_ii, and ROI_iii) respectively in open lake and Xukou Bay of Lake Taihu were used to determine threshold values from MODIS Rrc data directly (Figure 5). It should be noted that the values from in situ reflectance measurements could not be used for threshold 
development directly due to the complex optical conditions of the waterbody and impossibility to apply a comparative full atmospheric correction.

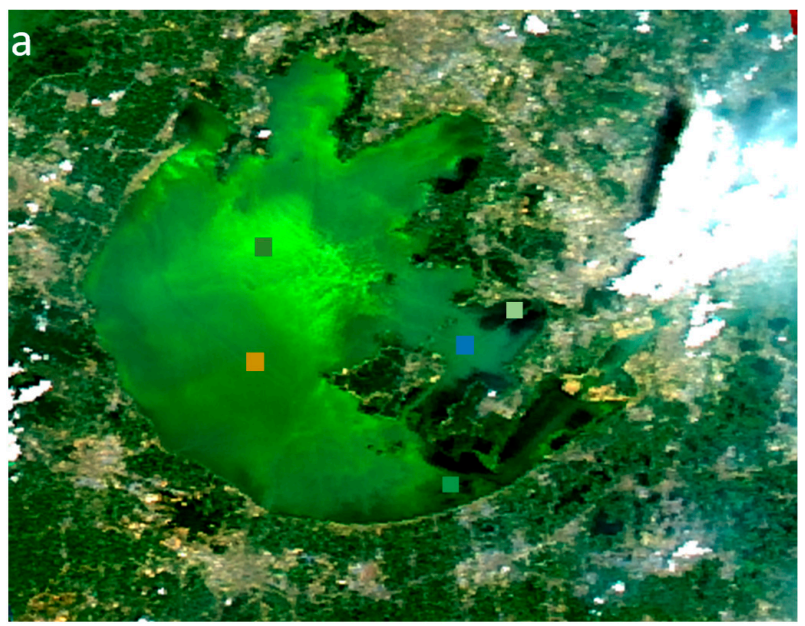

(a)

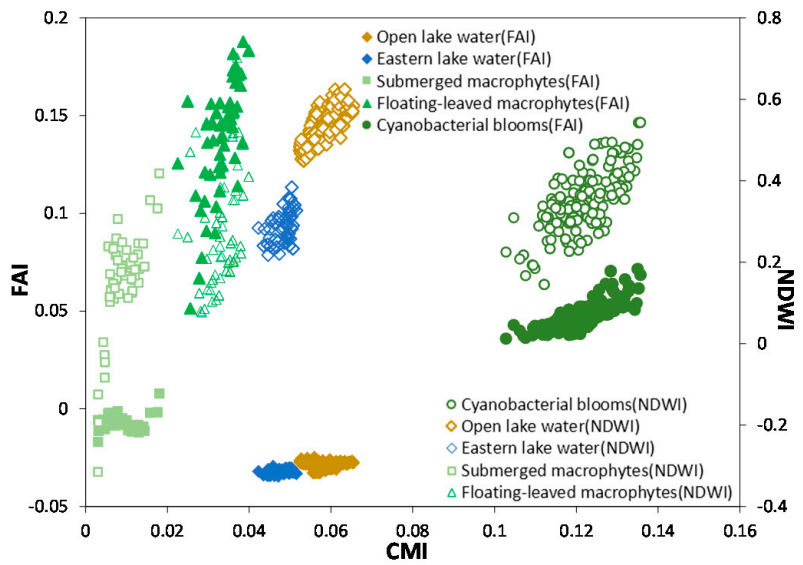

(b)

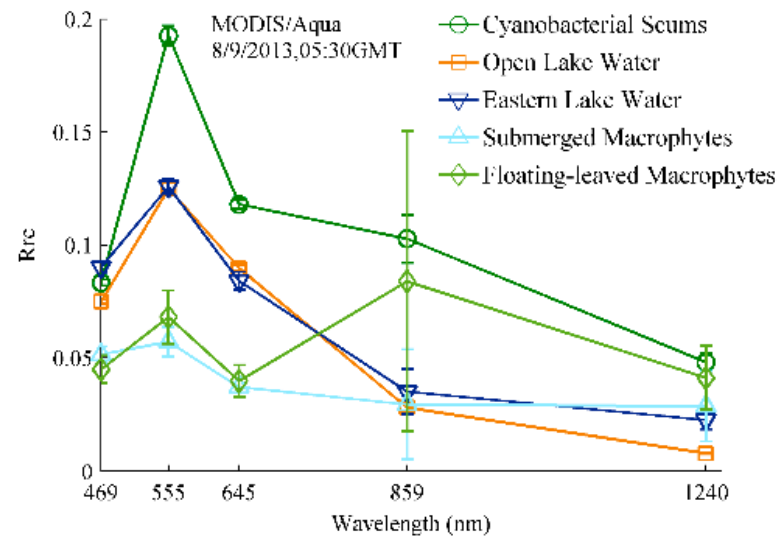

(c)

Figure 3. RGB image (a), the relationship of Cyanobacteria and Macrophytes Index (CMI), Floating Algae Index (FAI), and Normalized Difference Water Index (NDWI) (b) and the Rayleigh-corrected MODIS spectral reflectance $(\operatorname{Rrc}(\lambda))(\mathbf{c})$ of lake areas with different optical conditions on 8 September 2013 GMT. 


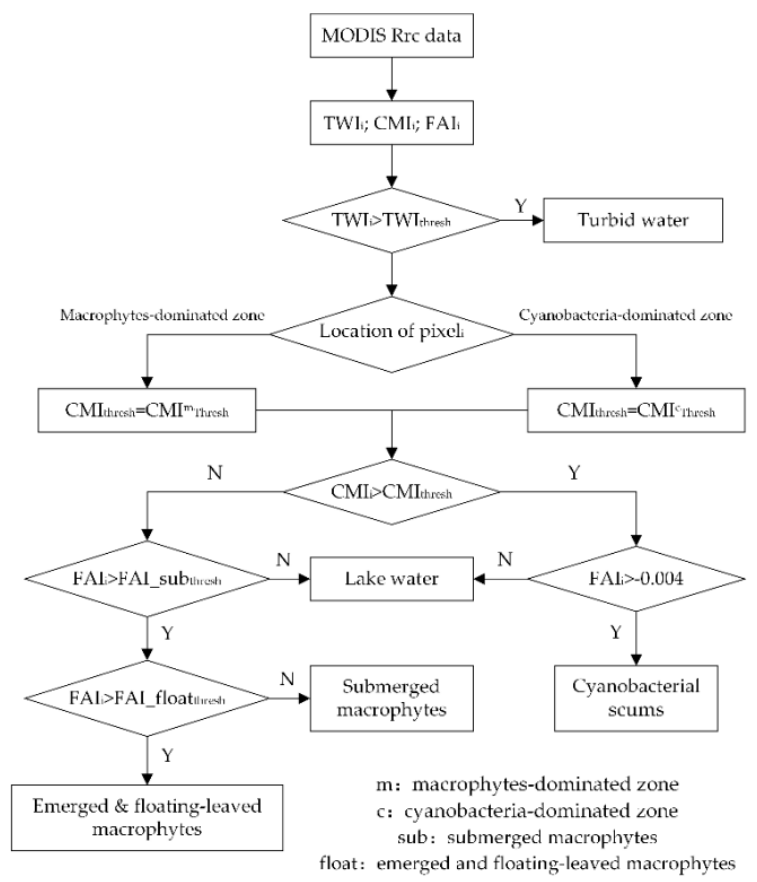

Figure 4. Classification decision tree to distinguish cyanobacterial scums and aquatic macrophytes in Lake Taihu.

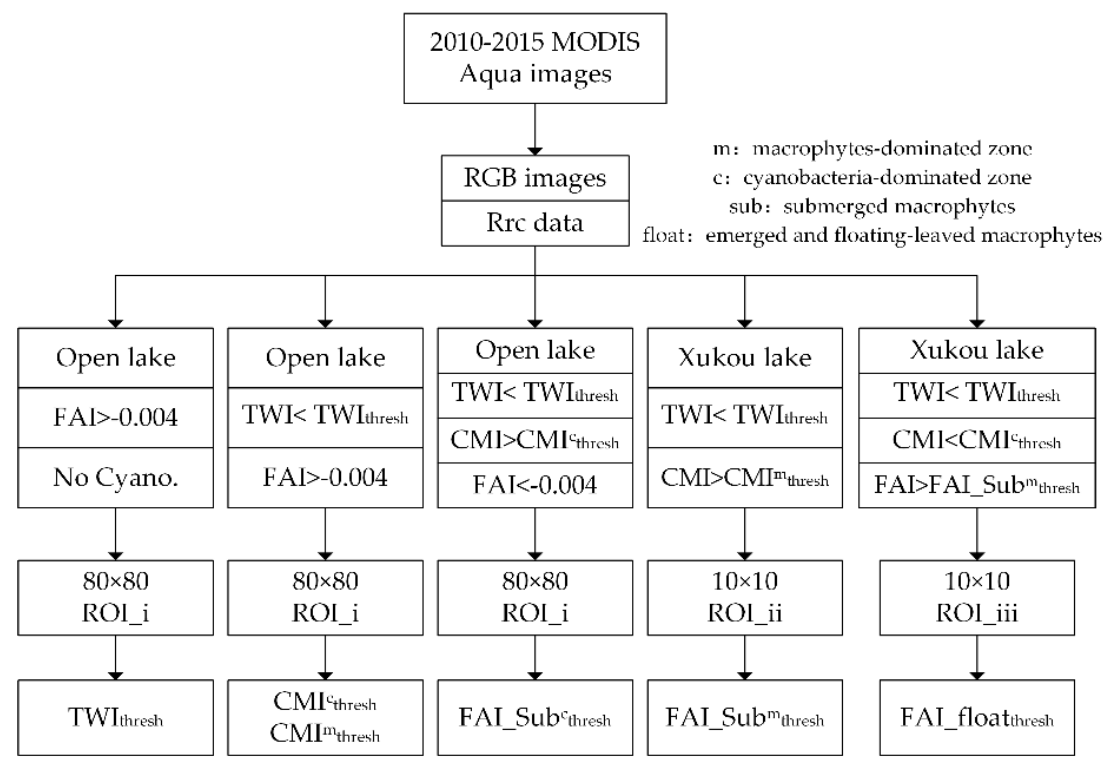

Figure 5. The flow chart for determining TWI, CMI, and FAI thresholds. ROI i was $80 \times 80$ pixels while ROI_ii and ROI_iii were $10 \times 10$ pixels, see Figure 1 for location.

\subsubsection{Accuracy Assessment and Validation}

Three approaches were used to validate our new classification tree: first, in situ remote sensing reflectance spectra were used to compare CMI to FAI and NDWI; second, user's accuracy, overall accuracy [99] and normalized accuracy [100] were calculated by comparing the satellite-derived distribution to the ground-truth results during 2013 and 2016; thirdly, aquatic macrophytes distributions derived from MODIS imageries were compared to those from $30 \mathrm{~m}$ spatial-resolution HJ-CCD imageries. 
User's accuracy $\left(p_{u}(i)\right)$ is a measure of the commission error associated with a class and is derived from the number of pixels correctly allocated to a class relative to the total number of pixels predicted to belong to that class in the accuracy assessment,

$$
p_{u}(i)=\frac{p_{c}(i)}{p_{t}(i)}
$$

where $p_{c}(i)$ is the number of correctly classified pixels of type $i$, and $p_{t}(i)$ is the number of total pixels of type $i$ based on the ground-truth measurements.

The overall accuracy $\left(p_{o}\right)$ was defined as the percentage of samples that were classified correctly and calculated using the following equation,

$$
p_{o}=\frac{\sum_{i=1}^{n} p_{c}(i)}{p_{t}}
$$

where $n$ is the total number of types that were classified, $p_{c}(i)$ is the number of correctly classified pixels of type $i$, and $p_{t}$ is the total number of pixels in the validation data set.

An iterative proportional fitting procedure which forces each row and column in the matrix to sum to one was used to normalized error metrics [100,101]. This process then changes the cell values along the major diagonal of the matrix (correct classifications) and therefore a normalized overall accuracy can be computed for each matrix by summing the major diagonal and dividing by the total of the entire matrix. The normalized accuracy is considered as a better representation of accuracy than the overall accuracy computed from the original matrix because it contains information about the off-diagonal cell values [100].

\subsection{Classification Method for HJ-CDD Data}

A spectral indices $\left(B_{4}-\sum_{j=1}^{3} B_{j}\right) /\left(B_{4}+\sum_{j=1}^{3} B_{j}\right)\left(\mathrm{SF}_{1}\right)$, the second principal components $\left(\mathrm{SF}_{2}\right)$ and the difference between the greenness index and the brightness index from the tasseled-cap transform $\left(\mathrm{SF}_{3}\right)$ were used to construct Luo's classification tree using $\mathrm{HJ}-\mathrm{CDD}$ data [66]. First, $\mathrm{SF}_{1}$ was utilized to detect emergent mocrophytes, then floating-leaved macrophytes were identified by $\mathrm{SF}_{2}$, and $\mathrm{SF}_{3}$ discriminated submerged macrophytes and open water lastly. The thresholds of SFs in the classification tree were determined by corresponding field investigation data.

\subsection{Analysis Methods}

\subsubsection{Atmospheric Effects}

Considering MODIS Rayleigh corrected reflectance used in our research, in order to estimate atmospheric effects on CMI, we simulated the influence of the different atmospheric conditions on CMI using in situ reflectance measurements and an atmospheric radiance transfer model in the absence of whitecaps and sun glint (Equation 1). Aerosol optical thickness (0-1 at intervals of 0.2$)$, six aerosol types (r30, 50, 70, 75, 80, and 85) and six typical solar/viewing geometry of Lake Taihu (oc1: solz $=40^{\circ}$, senz $=20^{\circ}$, phi $=40^{\circ} ;$ oc $2: \operatorname{solz}=40^{\circ}$, senz $=20^{\circ}$, phi $=-120^{\circ} ;$ oc $3:$ solz $=40^{\circ}$, senz $=40^{\circ}$, phi $=40^{\circ}$; oc4: solz $=40^{\circ}$, senz $=40^{\circ}$, phi $=-120^{\circ}$; oc5: solz $=60^{\circ}$, senz $=20^{\circ}$, phi $=-120^{\circ} ;$ oc6: solz $=60^{\circ}$, senz $=20^{\circ}$, phi $=40^{\circ}$ ) were extracted from SeaDAS LUTs.

\subsubsection{Mixed Pixels Effects}

The best spatial resolution of MODIS data is $250 \mathrm{~m}$, which is much rougher than that of Landsat TM/ETM+ and HJ-CCD. In order to assess mixed pixels effects on thresholds of CMI and FAI, a MODIS image with both of the cyanobacterial scums and all the kinds of macrophytes should be chosen in the following analysis. We therefore took the MODIS image on 9 August 2013 for an example to investigate the influence of mixed pixels on the thresholds of CMI and FAI by varying the fraction of 
cyanobacteria blooms, submerged macrophytes or emergent/floating macrophytes from $0 \%$ to $100 \%$ at intervals of $10 \%$. However, first, the $5 \times 5$ pixels covering with only one of lake water, cyanobacteria blooms, submerged macrophytes or emergent/floating macrophytes were detected based on in situ investigations in 2013. Also, the average upper $25 \%$ values of CMI and FAI were determined as the pure pixel thresholds for cyanobacterial scums or emergent/floating macrophytes. The average lower $25 \%$ values of CMI and FAI were decided as the pure pixel threshold for submerged macrophytes. Then the CMI and FAI means of $5 \times 5$ lake water pixels were used as the pure lake water thresholds. A simple linear model was chosen with two endpoints: one was pure lake water, and the other was pure cyanobacterial scums, submerged macrophytes or emerged/floating-leaved macrophytes.

\section{Results}

\subsection{Thresholds}

\subsubsection{TWI Threshold Determination for Turbid Waters}

Considering the location and timing of elevated turbidity in Lake Taihu, a region of interest (ROI_i) with $80 \times 80$ pixels in the open lake was chosen and 76 images from December to February were visually checked for cyanobacterial scums and aquatic macrophytes. All pixels, with FAI $>-0.004$, were put together to determine TWI thresholds (Figure 6a). Based on the near normal distribution with a mean $(\mu)$ and standard deviation $(\sigma)$ of 0.1326 and 0.0126 , the TWI threshold for turbid waters was $0.107(\mu-2 \sigma)$.

\subsubsection{Threshold Determination for Distinguishing Aquatic Macrophytes and} Cyanobacterial Scums

Based on the existed FAI threshold for cyanobacterial scums in Lake Taihu, FAI $>-0.004$ [47], the CMI threshold was based on 176 images from ROI_i, which satisfied TWI $\leq 0.107$ and FAI $>-0.004$ at the same time. The CMI distribution of cyanobacterial scums pixels was also in a normal fashion with $\mu=0.0455$ and $\sigma=0.0085$ (Figure 6b). The priori knowledge on Lake Taihu shows that the macrophytes-dominated zones are located in the east sections of the lake [65]. In order to minimize the false positive, we used two different CMI thresholds for detecting cyanobacterial scums in cyanobacteria-dominated zone and macrophytes-dominated zone (Figure 1). For cyanobacteria-dominated zones, we chose $0.0285(\mu-2 \sigma)$ as the $\mathrm{CMI}^{\mathrm{a}}{ }_{\text {thresh }}$, and for non-cyanobacteria-dominated zones we chose a more strict $0.0455(\mu)$ as $\mathrm{CMI}_{\text {thresh }}$.

\subsubsection{FAI Threshold Determination for Detection Different Types of Aquatic Macrophytes}

The published FAI threshold of -0.004 was used to distinguish cyanobacterial scum and water [47]. As FAI can also discriminate different types of aquatic macrophytes (Figure 3), and considering the small area of emergent macrophytes and coarse spatial resolution of MODIS, we combined emergent and floating macrophytes in one group. It should be noted that water quality in the macrophytes-dominated zone was much better than that in the cyanobacteria-dominated zone [79]. We decided to use two thresholds FAI_sub ${ }_{\text {thresh }}$ and FAI_sub ${ }_{\text {thresh }}$ in these two zones to discriminated waters and aquatic macrophytes respectively. FAI_sub ${ }^{\mathrm{a}}$ thresh was based on ROI_i (Figure 6c) where TWI $<0.107$, CMI $<0.0285$ and FAI $<-0.004$. Similarly, FAI_sub ${ }_{\text {thresh }}$ was determined from ROI_ii (Figure 6d), where TWI $<0.107, \mathrm{CMI}<0.0455$ and FAI $<-0.004$. FAI_sub ${ }_{\text {thresh }}$ and FAI_subg ${ }_{\text {thresh }}$ were -0.0122 and $-0.011(\mu-2 \sigma)$ respectively. In the same way, ROI_iii in Xukou Bay was used to determine the FAI threshold of 0.05 for submerged and emergent/floating macrophytes, interestingly the same FAI value used by Oyama with Landsat TM/ETM [67].

All of the thresholds have been summarized in Table 5. 

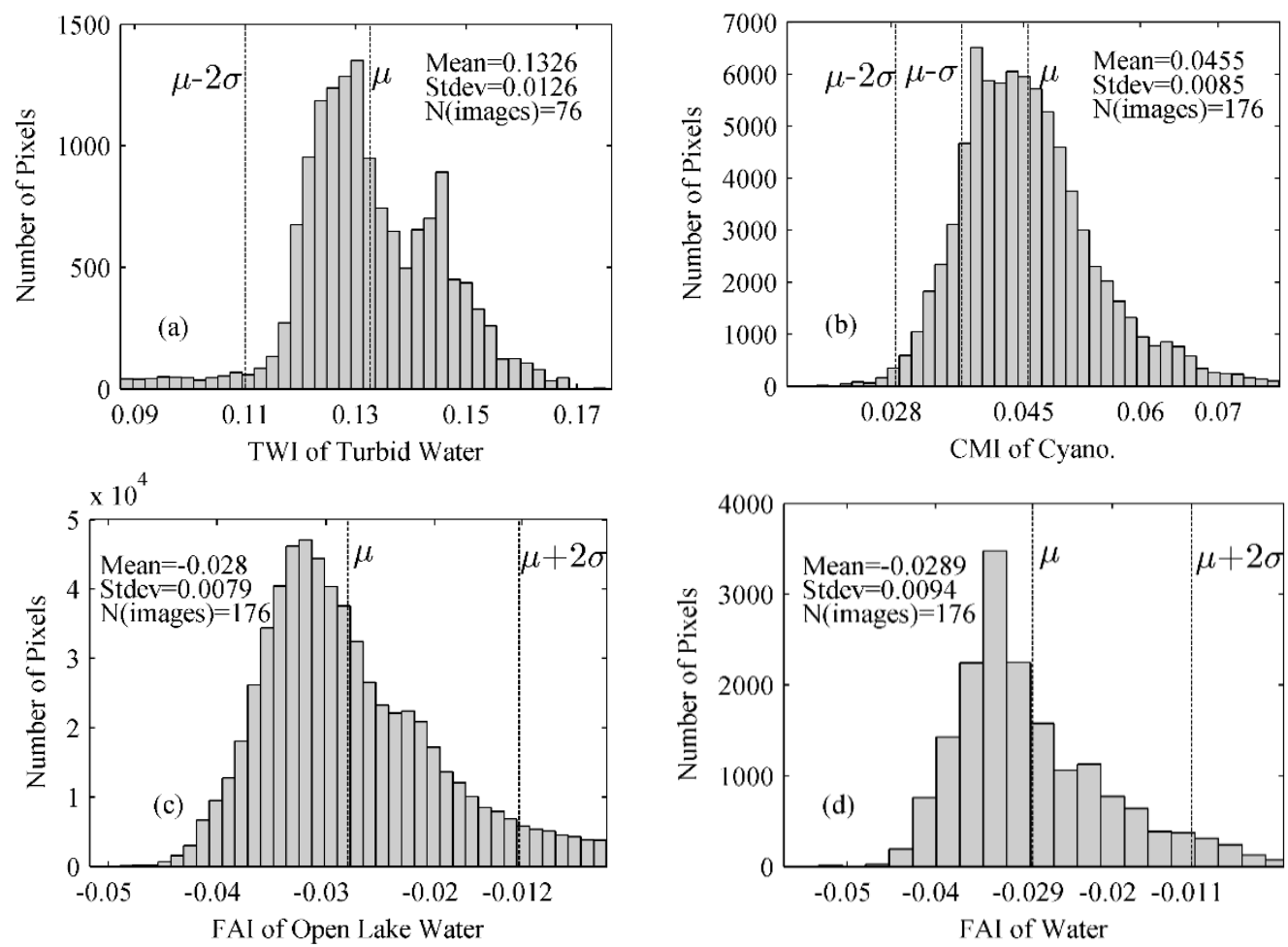

Figure 6. Distribution of TWI (a), CMI (b) and FAI (c,d) for images to distinguish thresholds for turbid water, cyanobacterial scums, submerged macrophytes, and floating macrophytes.

Table 5. The thresholds of TWI, CMI, and FAI used in the new classification method.

\begin{tabular}{cccc}
\hline Index & Usage & $\begin{array}{c}\text { Cyanobacteria-Dominated } \\
\text { Zone }\end{array}$ & $\begin{array}{c}\text { Macrophytes } \\
\text { Dominated Zone }\end{array}$ \\
\hline TWI & To detect high turbid water & & 0.107 \\
CMI & To distinguish lake water with cyanobacterial scums & 0.0285 & 0.0455 \\
FAI_cyano & or with macrophytes & -0.004 & -0.004 \\
FAI_sub $_{\text {thresh }}$ & To detect cyanobacterial scums & -0.0122 & -0.011 \\
FAI_float thresh & To detect submerged macrophytes & 0.05 & 0.05 \\
\hline
\end{tabular}

\subsection{Validation by in Situ RRS Measurements}

We first validated the applicability of CMI, FAI, and NDWI to distinguish lake water, cyanobacterial scums, submerged macrophytes, and emergent/floating macrophytes using in situ reflectance spectra of 2014 and 2015. All of these indices were calculated by in situ measured reflectance in simulated MODIS bands (Figure 7).

FAI was effective at separating lake water and others, but less useful for distinguishing cyanobacterial scums and aquatic macrophytes (Figure $7 \mathrm{~b}$ ). In contrast, CMI showed significant differences between the cyanobacterial scums and aquatic macrophytes, but was less useful for detecting open lake waters (Figure 7a). The modelled MODIS band $2(841-876 \mathrm{~nm}$ ) and band 6 (1628-1652 nm) from in situ spectra were chosen to estimate NDWI, which also showed a good separation between cyanobacterial scums and floating-leaved macrophytes from Figure $7 \mathrm{c}$ as that achieved using Landsat TM/ETM+ [67]. However, if MODIS Rrc data were used, NDWI was less useful due to Figure $3 \mathrm{~b}$. This may be the result of very thick cyanobacterial scums, relative disperse and sparse aquatic macrophytes, and turbid waters as well as the spectral differences between MODIS and Landsat TM. This validation by in situ Rrs indicated the improved effectiveness of combining CMI and FAI. 


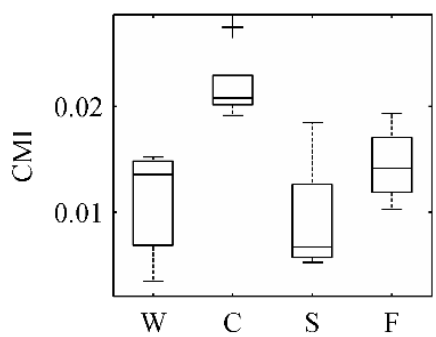

(a)

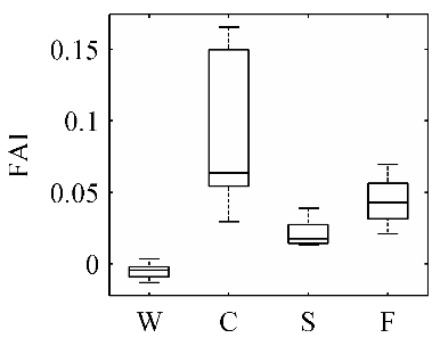

(b)

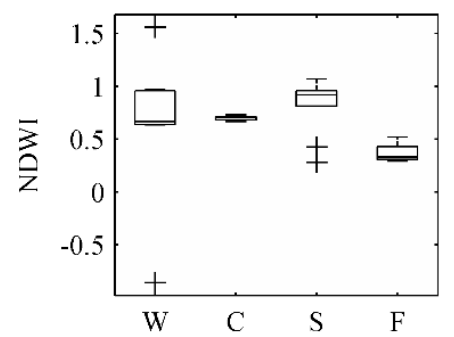

(c)

Figure 7. Box-and-whisker plots of CMI (a), FAI (b) and NDWI (c) for lake water, cyanobacterial scums, macrophytes based on in situ reflectance spectra of Lake Taihu. The solid line in the box represents the median value. The upper and lower fences represent the 1st and 3rd quartiles (Q1 and Q3), respectively. The lower and upper whiskers were calculated from (Q1 $-1.5 \times I Q R)$ and $(\mathrm{Q} 3+1.5 \times \mathrm{IQR})$, respectively, where IQR is the inter quartile range represented by the width of the box (i.e., Q3 - Q1). The data above or under the whisker were defined as the outliers and are shown as cross. (W: Lake water; C: Cyanobacterial scums; S: Submerged macrophytes; F: Emergent and floating macrophytes).

\subsection{Validation by Field Investigation}

To verify the stability and accuracy of the new method, we validated the predicted results with synchronous ground-truth investigations in Lake Taihu (Table 6). From 2013-2016, the user's accuracy of the submerged macrophytes, emergent and floating macrophytes, cyanobacterial scums and lake water was $83 \%-89 \%, 79 \%-83 \%, 75 \%-92 \%$ and, $92 \%-100 \%$ respectively, and the overall classification accuracy each year was $87 \%, 92 \%, 80 \%$, and $86 \%$, respectively. Based on the off-diagonal matrix values, the normalized accuracy was lower than the overall classification accuracy, which was $86.2 \%, 62.6 \%$, $56.5 \%$, and $81.0 \%$ for 2013-2016 respectively. In total, the overall classification accuracy and normalized accuracy was almost similar, $86.0 \%$ and $86.8 \%$ respectively. The classification accuracy was influenced by: the number and spatial distribution of ground-truth data [68] and the spatial resolution of MODIS where mixed pixels effects could lower the overall accuracy.

Table 6. Accuracy assessment of classification results from 2013 to 2016.

\begin{tabular}{|c|c|c|c|c|c|c|c|c|}
\hline \multirow[b]{2}{*}{ Year } & \multirow[b]{2}{*}{ Measured } & \multicolumn{7}{|c|}{ Predicted } \\
\hline & & $S$ & $E \& F$ & $\mathrm{C}$ & $\mathbf{W}$ & $\begin{array}{c}\text { User's } \\
\text { Accuracy }\end{array}$ & $\begin{array}{c}\text { Overall } \\
\text { Accuracy }\end{array}$ & $\begin{array}{c}\text { Normalized } \\
\text { Accuracy }\end{array}$ \\
\hline \multirow{3}{*}{2013} & S & 71 & 5 & & 4 & $89 \%$ & \multirow{3}{*}{$87 \%$} & \multirow{3}{*}{$86.2 \%$} \\
\hline & $E \& F$ & 7 & 26 & & & $79 \%$ & & \\
\hline & W & 3 & & & 34 & $92 \%$ & & \\
\hline \multirow{3}{*}{2014} & $S$ & 11 & 1 & \multirow{3}{*}{11} & 1 & $85 \%$ & \multirow{3}{*}{$92 \%$} & \multirow{3}{*}{$62.6 \%$} \\
\hline & $\mathrm{C}$ & & & & 1 & $92 \%$ & & \\
\hline & W & & & & 3 & $100 \%$ & & \\
\hline \multirow{3}{*}{2015} & $\mathrm{~S}$ & 10 & & & 2 & $83 \%$ & \multirow{3}{*}{$80 \%$} & \multirow{3}{*}{$56.5 \%$} \\
\hline & $E \& F$ & 1 & 5 & & & $83 \%$ & & \\
\hline & C & 1 & & 3 & & $75 \%$ & & \\
\hline \multirow{3}{*}{2016} & $\mathrm{~S}$ & 7 & & \multirow{3}{*}{3} & 1 & $88 \%$ & \multirow{3}{*}{$86 \%$} & \multirow{3}{*}{$81.0 \%$} \\
\hline & C & & & & 1 & $75 \%$ & & \\
\hline & W & 1 & & & 16 & $94 \%$ & & \\
\hline \multirow{4}{*}{ Total } & $\mathrm{S}$ & 99 & 6 & & 8 & $88 \%$ & \multirow{4}{*}{$86 \%$} & \multirow{4}{*}{$86.8 \%$} \\
\hline & $E \& F$ & 8 & 31 & & & $79 \%$ & & \\
\hline & C & 1 & & 17 & 2 & $85 \%$ & & \\
\hline & W & 4 & & & 53 & $93 \%$ & & \\
\hline
\end{tabular}

S: Submerged macrophytes; E \& F: Emergent \& floating macrophytes; C: Cyanobacterial scums; W: Water. 


\subsection{Validation by HJ-CCD Data}

High-spatial resolution HJ-CCD data were used to validate spatial distributions of water, cyanobacterial scums and different aquatic macrophytes for 9 and 16 August, and 16 and 26 September 2013 (Figure 8). Aquatic vegetation spatial distributions on 16 August and 26 September 2013 were provided only in the eastern part of Lake Taihu by Luo's CT method [66] using HJ-CCD data. The two datasets showed consistent spatial distributions of aquatic macrophytes in the macrophytes-dominated areas: in the south shore of Gonghu Bay, there existed many submerged macrophytes and sparse floating macrophytes; submerged macrophytes dominated Xukou Bay; floating macrophytes were mainly located in the East lake especially in summer. However, emergent macrophytes distributed dispersedly close to the shores were more difficult for MODIS data to identify.
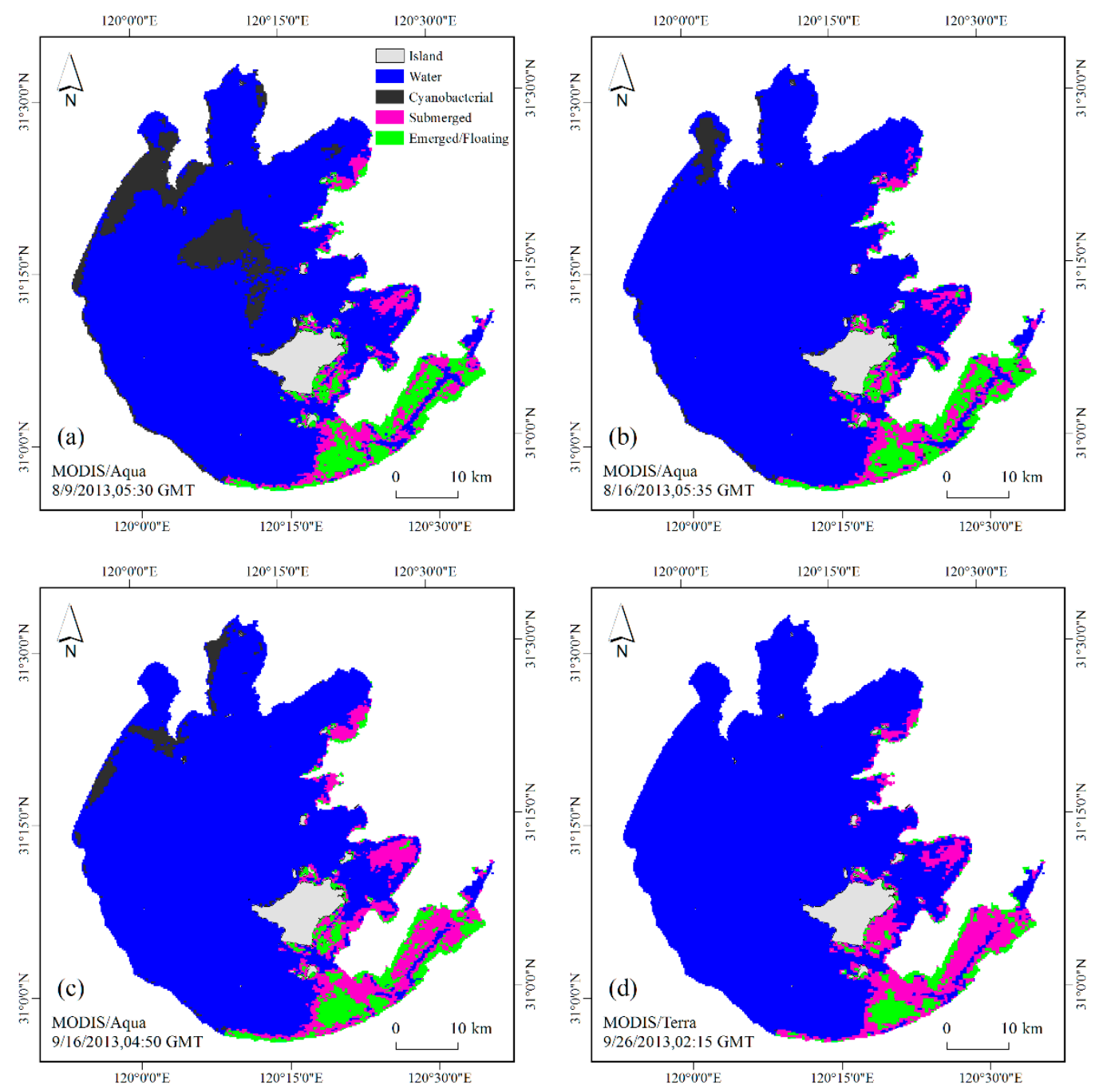

Figure 8. Spatial distributions of lake water, cyanobacterial scums and different aquatic macrophytes in Lake Taihu on 9 (a) and 16 (b) August, and 16 (c) and 26 (d) September 2013.

The expected temporal consistency was met, as submerged and emergent/floating macrophytes in the macrophytes-dominated zone were 174.5 and $178.3 \mathrm{~km}^{2}$ on 16 August, and 255.7 and $105.6 \mathrm{~km}^{2}$ on 26 September, respectively and their location was consistent (Figure 8). Cyanobacterial scums showed a much larger variation, changing from 68.4 to $0.75 \mathrm{~km}^{2}$ over the same period. 


\section{Discussion}

\subsection{Data Quality versus Data Quantity}

Time-series and trend analyses for aquatic vegetation, both macro and micro, in inland water bodies have been difficult to examine using satellite ocean color data due to challenging atmospheric conditions (e.g., clouds, thick aerosols, and sun glint) [72]. This complicates the separation of in-water reflectance from the top of atmospheric reflectance. The use of $\operatorname{Rrc}(869)>0.027$ to screen cloud pixels and low quality data significantly reduced data availability for Lake Taihu even under cloud-free and glint-free conditions [72]. Not only thick aerosols but also cyanobacteria blooms and aquatic macrophytes can increase reflectance in the near infra-red and shortwave infra-red wavelengths. For turbid waters, Wang and Shi recommended a cloud threshold of $\operatorname{Rrc}(1240)=0.0235$ and $\operatorname{Rrc}(1640)=0.0215$ [102], while Hu suggested $\operatorname{Rrc}(1640)=0.03$ [47]. None of these are suitable for the complex atmospheric, aquatic, and ecological conditions of Lake Taihu, where thick aerosols, sun glint, cyanobacteria blooms, aquatic macrophytes, and elevated turbidity all co-exist. In order to avoid false positive cloud masking from cyanobacteria blooms and aquatic macrophytes, we utilized Qi's $\operatorname{Rrc}(555)>0.25$ [72] and $\operatorname{Rrc}(1240)>0.10$ as constraint conditions for cloud masking. This resulted in $>90 \%$ valid data coverage per image for every climatological month (Figure 9). In comparison, the mean valid data coverage for the $\operatorname{Rrc}(1240)<0.0235$ threshold was $35 \%-74 \%$.

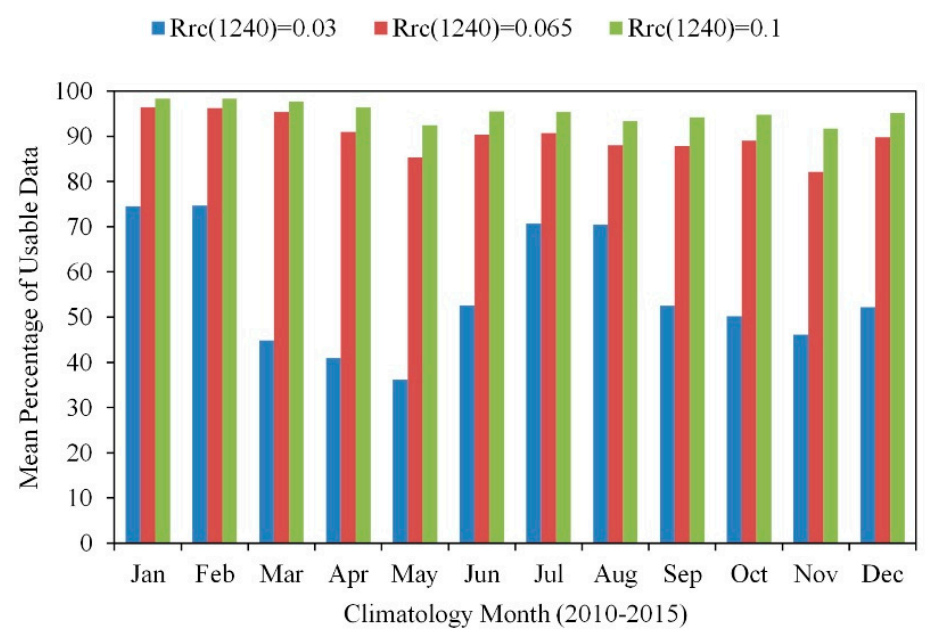

Figure 9. Mean percentage of usable data per image during each climatological month, based on different $\operatorname{Rrc}(1240)$ thresholds.

\subsection{Use in Highly Turbid Waters}

For shallow and turbid Lake Taihu, re-suspended solids have a major impact on visible and near infra-red reflectance spectra [103]. A comparison of reflectance spectra from cyanobacteria blooms, typical aquatic macrophytes, and turbid waters with different suspended solid (SS) concentrations shows that CMIs increased at higher suspended solid concentrations (Figure 10), impacting the detection of cyanobacteria blooms and emergent/floating macrophytes. Figure 11 is an example showing that the turbid water index, TWI, avoided these misclassifications, even under high wind and high turbidity conditions. MODIS RGB image (Figure 11a) showed lake water in the open lake was yellow and very turbid especially close to the west $(\mathrm{W})$ and south $(\mathrm{S})$ lakeshores, correspondingly CMI(W: $0.040 \pm 0.003 ;$ S: $0.043 \pm 0.003$ ) and FAI (W: $-0.006 \pm 0.008 ;$ S: $0.0001 \pm 0.008$ ) of high turbid water were much higher than the other regions (Figure 11b,c). Therefore, high turbid water could be misclassified to cyanobacterial scums in cyanobacteria-dominated zone and submerged macrophytes in macrophyte dominated zones (Figure 11d). (W: $0.141 \pm 0.014 ;$ S: $0.147 \pm 0.010$ ) As our new 
method considered the disturbance from turbid water via TWI (Figure 11f), original false positives for cyanobacteria blooms were rejected.

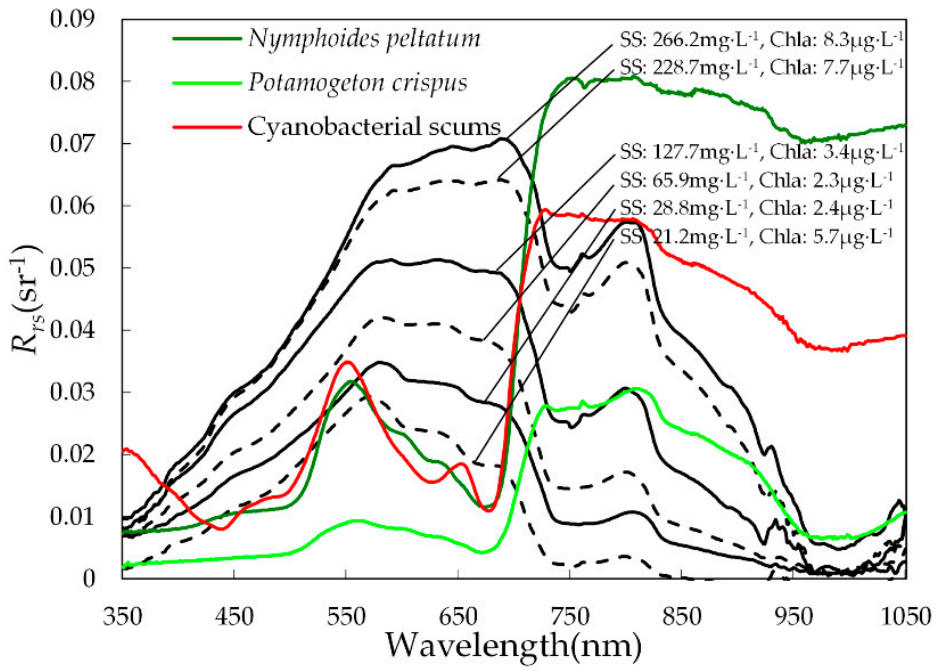

Figure 10. A comparison of in situ water leaving reflectance (Rrs) spectra for different aquatic macrophytes under different concentrations of suspended solids and cyanobacterial scums in Lake Taihu.

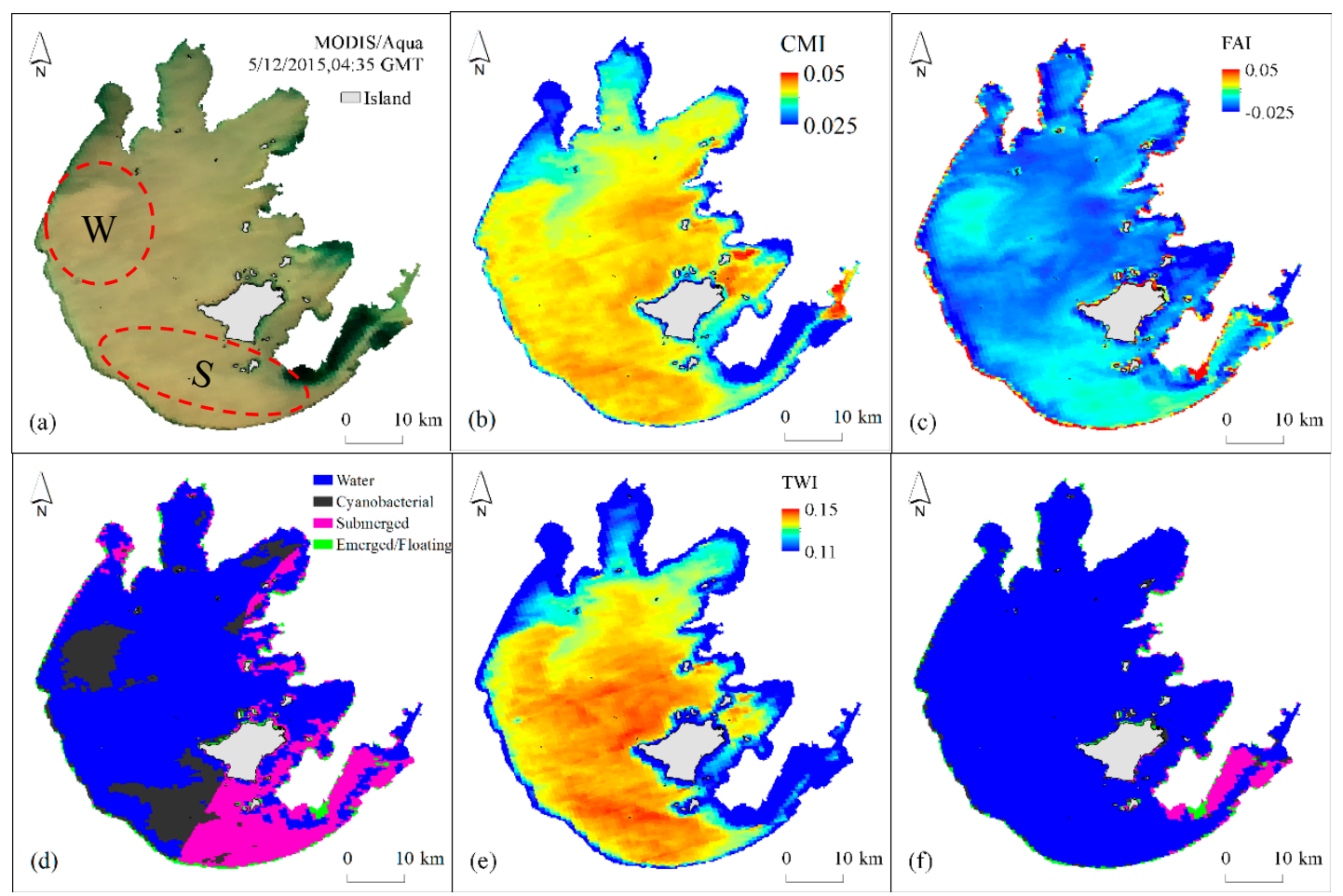

Figure 11. Spatial distributions of RGB (a), CMI (b), FAI (c) and TWI (e) based on MODIS Aqua image of 12 May 2015; and spatial distribution of lake water, cyanobacterial scums, and macrophytes in Lake Taihu before (d) and after (f) using TWI.

\subsection{Impact of Black Waters}

Black waters are another typical environmental phenomenon in eutrophic lakes, often associating to lake areas with cyanobacteria blooms and macrophyte stands [104]. They are characterized by high absorption due to elevated concentrations of colored dissolved organic matter (CDOM) [104,105]. 
In Lake Taihu, further studies on the 2007 algal bloom event indicated that the intrusion of a black water bloom in the main water intake of Wuxi City was the key cause of the water source crisis [106]. Studies show that Zhanshan Bay, Meiliang Bay, and Gonghu Bay were the main sensitive area to black waters in Lake Taihu [104,107,108], all areas of high-frequency cyanobacterial scums [47]. Attempts to use remote sensing to detect black waters have found that interference by cyanobacteria blooms and submerged macrophytes can be significant [105]. Field observations indicate that black waters in Lake Taihu have limited spatial and temporal scope, usually persisting for less than five days. They occur in areas of submerged macrophytes (i.e., Potamogeton crispus) from March to May [109]. By integrating the static location and growth period of submerged macrophytes, the possible interference of black waters on the remote sensing of macrophyte and bloom was achieved.

\subsection{Atmospheric Effects}

The impact of aerosol thickness, aerosol type, and solar/viewing geometry on classification indices was variable. The CMI value was supposed as 0.04 at $\mathrm{AOT}(555)=0$, aerosol type $=\mathrm{r} 30$, solz $=40^{\circ}$, senz $=20^{\circ}$, and phi $=40^{\circ}$. CMI was least sensitive to aerosol thickness, as only $12.1 \%$ changed when AOT(555) varied from 0 to 1 (Figure 12a). Although the effects of aerosol thickness in shorter wavelengths are stronger than those in longer wavelengths [110], the baseline subtraction of CMI, like FAI, helped reduce the effects from different aerosol thicknesses. CMI changed $<0.5 \%$ and $<15.2 \%$ with different aerosol types and solar/viewing geometry, respectively (Figure 12b,c). FAI has been shown to be less sensitive to changes in aerosol and observing conditions [46].
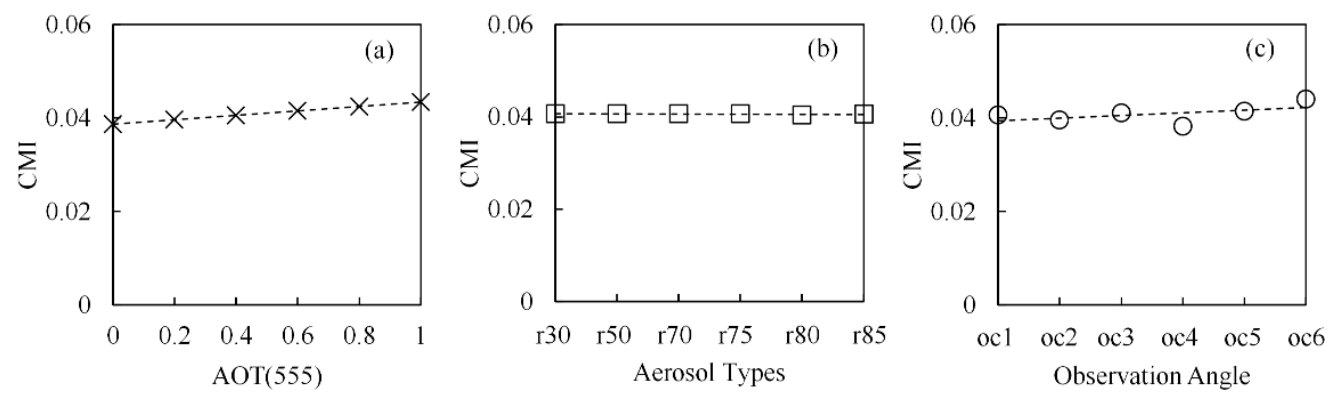

Figure 12. CMI value variation with changing atmospheric conditions: optical thickness (a), aerosol type (b) and solar/viewing geometry (c), based on model simulations (oc1: solz $=40^{\circ}$, senz $=20^{\circ}$, phi $=40^{\circ} ;$ oc $2:$ solz $=40^{\circ}$, senz $=20^{\circ}$, phi $=-120^{\circ} ;$ oc $3:$ solz $=40^{\circ}$, senz $=40^{\circ}$, phi $=40^{\circ} ;$ oc $4: \operatorname{solz}=40^{\circ}$, $\operatorname{senz}=40^{\circ}$, phi $=-120^{\circ} ;$ oc5: $\operatorname{solz}=60^{\circ}$, senz $=20^{\circ}$, phi $=-120^{\circ} ;$ oc6: solz $=60^{\circ}$, senz $=20^{\circ}$, phi $=40^{\circ}$ ).

\subsection{Mixed Pixels Effects}

Differences between the classification and ground-truth observations (Table 4) are likely to have resulted from scale effects. Mixed MODIS pixels containing both open lake water and cyanobacteria blooms or aquatic macrophytes were validated in field observations. Figure 13a shows that CMI values of different fractions of cyanobacteria blooms were above the CMI thresholds of 0.0455 in macrophytes-dominated zones and 0.0285 in cyanobacteria-dominated zones. This confirmed that the CMI thresholds detected cyanobacteria blooms correctly regardless of where cyanobacterial scums occurred. The CMI threshold of 0.0455 allowed for the identification of aquatic macrophytes in macrophytes-dominated zones (Figure 13b), not only emergent/floating macrophytes but also submerged macrophytes. In cyanobacteria-dominated zone, however, the CMI threshold of 0.0285 misclassified emergent/floating macrophytes as cyanobacteria blooms, and similarly submerged macrophytes were detected as cyanobacteria when submerged macrophytes coverage was lower than $33.3 \%$. Usually, few emergent/floating macrophytes grow in cyanobacteria-dominated zones of Lake Taihu [111]. Due to this, we analyzed the influence of the CMI threshold of 0.0285 on the detection of the pixel mixing with cyanobacteria blooms and submerged macrophytes (Figure 13c). 
Submerged macrophytes were classified correctly only when their fraction was more than $79.2 \%$. In macrophyte-dominated zones, the CMI threshold of 0.0455 distinguished cyanobacteria blooms and aquatic macrophytes perfectly; but in cyanobacteria-dominated zones, the CMI threshold of 0.0285 was more appropriate for bloom detection.

The FAI threshold of -0.011 correctly detected submerged macrophytes from lake water when their fractions were larger than $47.0 \%$ (Figure 14), and when the fraction of emergent/floating macrophytes was more than $23.8 \%$, the mixed pixel could be classified as emergent/floating macrophytes due to the FAI threshold of 0.05 .
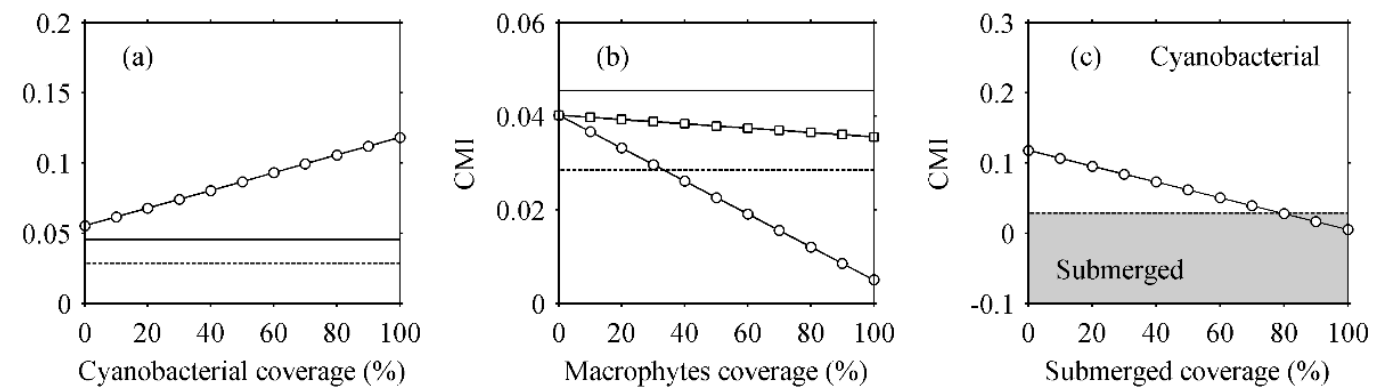

Figure 13. (a-c) CMI variation in different lake water conditions, dominated by cyanobacterial scums and aquatic macrophytes. The dotted line represents the CMI threshold between cyanobacterial scums and different aquatic macrophytes in cyanobacteria-dominated zone, and the full line represents the CMI threshold between cyanobacterial scums and different aquatic macrophytes in macrophyte-dominated zones. The gray areas represent the area recognized as submerged macrophytes by the threshold.
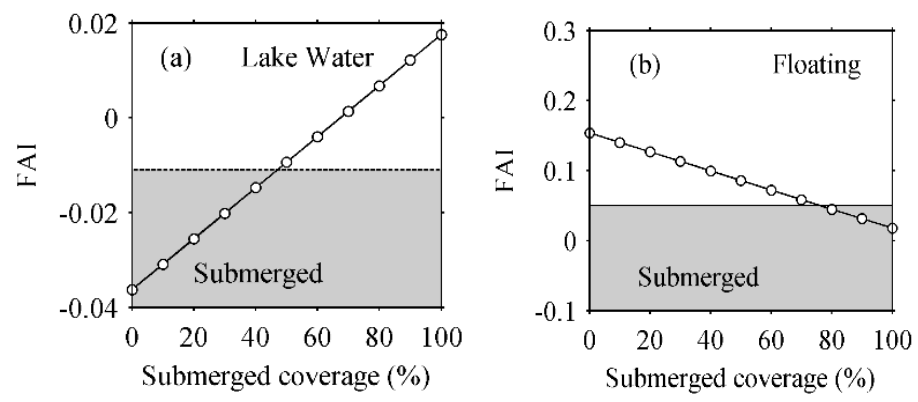

Figure 14. (a,b) FAI variation with different composition of lake water and aquatic macrophytes. The dotted line represents the FAI threshold between lake water and submerged macrophytes, and the full line represents the FAI threshold between submerged macrophytes and emergent/floating macrophytes. The gray areas represent the area recognized as submerged macrophytes by the threshold.

\section{Conclusions}

In this study, a new method to examine the spatial distribution of cyanobacterial scums and macrophyte vegetation dominated areas of optically complex shallow lakes was developed. The approach was validated by in situ reflectance spectra, field investigations and high spatial resolution HJ-CCD data. The results show an overall classification accuracy of $86 \%$ and a normalized classification accuracy of $86.8 \%$ with a specific accuracy of $88 \%, 79 \%, 85 \%$, and $93 \%$ for submerged macrophytes, emergent/floating macrophytes, cyanobacterial scums, and lake water, respectively. The possibility to separate open lake water, areas dominated by cyanobacterial scums and those with different aquatic macrophytes opens new possibilities to explore the impacts of large scale changes in lake and catchment management.

The MODIS indices were first developed; TWI, CMI, and FAI were tested in the highly complex atmospheric and aquatic optical conditions of a large highly eutrophic and shallow lake in southeast 
China. The classification method addressed first areas of high turbidity (TWI), then separated pixels into lake waters with cyanobacterial scums or aquatic macrophytes (CMI). Lastly, FAI thresholds were used to separate cyanobacterial scums and lake water, and to classify the remaining areas into submerged macrophytes, emergent/floating macrophytes or lake water.

The new method provided high accuracy, low sensitivity to changing atmospheric conditions, high background reflectance (turbidity) or absorption (black waters), and mixed-pixels effects. The overall approach to combining specific indices in a decision tree to identify and separate lake areas with dominant optical properties can easily be extended to other lake ecosystems. The indices applied in the present study are those most appropriate to shallow eutrophic lakes, therefore most directly applicable to these more complex waterbodies. In deeper or less impacted lakes, the use of turbidity indices (TWI) is not appropriate, and more specific indices related to the lake- specific dominant optical components (e.g., CDOM) should be used. Furthermore, additional testing would be required for lakes with significantly different types of macrophytes or where macrophytes and algae are both present. Further validation to test the applicability of the new method using other satellite sensors would extend the use of this approach.

Acknowledgments: This work was supported by Key Program of the National Natural Science Foundation of China (Grant No. 41431176 \& No. 41671371), the National Natural Science Foundation of China (Grant No. 41471287), National Key Technology Research and Development Program of the Ministry of Science and Technology of China during the "12th Five-Year Plan" (Grant No. 2015BAD13B06) and the ESA-MOST (China) Dragon 4 Cooperation Program project 32442. Field data were provided by Scientific Data Sharing Platform for Lake and Watershed, Nanjing Institute of Geography and Limnology, Chinese Academy of Sciences. The Rrc data of MODIS images were processed and provided by Chuanmin Hu and his optical oceanography laboratory, University of South Florida. We also express our gratitude to Minwei Zhang for his support on atmospheric transfer simulation.

Author Contributions: Y.Z. and Q.L. developed the idea for the study and its design. Q.L., J.L. and M.H. were responsible for the construction and validation of the dataset. Q.L., Y.Z., R.M. and S.L. shared in the analysis and development of the discussion. Q.L., Y.Z. and S.L. finalized the manuscript. All authors read and approved the manuscript.

Conflicts of Interest: The authors declare no conflict of interest.

\section{References}

1. Huisman, J.; Matthijs, H.C.P.; Visser, P.M.E. Harmful Cyanobacteria; Springer: Dordrecht, The Netherlands, 2005.

2. Granéli, E.; Turner, J.T.E. Ecology of Harmful Algae; Springer: Berlin/Heidelberg, Germany, 2006.

3. Guo, L. Doing battle with the green monster of Taihu Lake. Science 2007, 317. [CrossRef] [PubMed]

4. Duarte, C.M.; Middelburg, J.J.; Caraco, N. Major role of marine vegetation on the oceanic carbon cycle. Biogeosciences 2006, 2, 1-8. [CrossRef]

5. Orth, R.J.; Carruthers, T.J.B.; Dennison, W.C.; Duarte, C.M.; Fourqurean, J.W.; Heck, K.L.; Hughes, A.R.; Kendrick, G.A.; Kenworthy, W.J;; Olyarnik, S.; et al. A global crisis for seagrass ecosystems. BioScience 2006, 56, 987-996. [CrossRef]

6. Carr, J.; D'Odorico, P.; McGlathery, K.; Wiberg, P. Stability and bistability of seagrass ecosystems in shallow coastal lagoons: Role of feedbacks with sediment resuspension and light attenuation. J. Geophys. Res. 2010, 115. [CrossRef]

7. Kolada, A. The use of aquatic vegetation in lake assessment: Testing the sensitivity of macrophyte metrics to anthropogenic pressures and water quality. Hydrobiologia 2010, 656, 133-147. [CrossRef]

8. Scheffer, M.; van Nes, E.H. Shallow lakes theory revisited: Various alternative regimes driven by climate, nutrients, depth and lake size. Hydrobiologia 2007, 584, 455-466. [CrossRef]

9. Xue, K.; Zhang, Y.; Duan, H.; Ma, R.; Loiselle, S.; Zhang, M. A remote sensing approach to estimate vertical profile classes of phytoplankton in a eutrophic lake. Remote Sens. 2015, 7, 14403-14427. [CrossRef]

10. Walsby, A.E. Gas vesicles. Microbiol. Rev. 1994, 58, 94-144. [CrossRef] [PubMed]

11. Matthews, M.W. A current review of empirical procedures of remote sensing in inland and near-coastal transitional waters. Int. J. Remote Sens. 2011, 32, 6855-6899. [CrossRef]

12. Odermatt, D.; Gitelson, A.; Brando, V.E.; Schaepman, M. Review of constituent retrieval in optically deep and complex waters from satellite imagery. Remote Sens. Environ. 2012, 118, 116-126. [CrossRef] 
13. Patissier, D.B.; Gower, J.F.R.; Dekker, A.G.; Phinn, S.R.; Brando, V.E. A review of ocean color remote sensing methods and statistical techniques for the detection, mapping and analysis of phytoplankton blooms in coastal and open oceans. Prog. Oceanogr. 2014, 123, 123-144. [CrossRef]

14. Peñuelas, J.; Gamon, J.A.; Griffin, K.L.; Field, C.B. Assessing community type, plant biomass, pigment composition, and photosynthetic efficiency of aquatic vegetation from spectral reflectance. Remote Sens. Environ. 1993, 46, 110-118. [CrossRef]

15. Gitelson, A.A.; Kaufman, Y.J.; Stark, R.; Rundquist, D.C. Novel algorithms for remote estimation of vegetation fraction. Remote Sens. Environ. 2002, 80, 76-87. [CrossRef]

16. Silva, T.S.; Costa, M.P.; Melack, J.M.; Novo, E.M. Remote sensing of aquatic vegetation: Theory and applications. Environ. Monit. Assess. 2008, 140, 131-145. [CrossRef] [PubMed]

17. Olmanson, L.G.; Bauer, M.E.; Brezonik, P.L. A 20-year Landsat water clarity census of Minnesota's 10,000 lakes. Remote Sens. Environ. 2008, 112, 4086-4097. [CrossRef]

18. Bresciani, M.; Adamo, M.; De Carolis, G.; Matta, E.; Pasquariello, G.; Vaičiūtè, D.; Giardino, C. Monitoring blooms and surface accumulation of cyanobacteria in the curonian lagoon by combining MERIS and ASAR data. Remote Sens. Environ. 2014, 146, 124-135. [CrossRef]

19. Duan, H.; Ma, R.; Xu, X.; Kong, F.; Zhang, S.; Kong, W.; Hao, J.; Shang, L. Two-decade reconstruction of algal blooms in China's lake Taihu. Environ. Sci. Technol. 2009, 43, 3522-3528. [CrossRef] [PubMed]

20. Kahru, M.; Savchuk, O.P.; Elmgren, R. Satellite measurements of cyanobacterial bloom frequency in the Baltic Sea: Interannual and spatial variability. Mar. Ecol. Prog. Ser. 2007, 343, 15-23. [CrossRef]

21. Kahru, M.; Elmgren, R. Multidecadal time series of satellite-detected accumulations of cyanobacteria in the Baltic Sea. Biogeosciences 2014, 11, 3619-3633. [CrossRef]

22. Groom, S.B.; Holligan, P.M. Remote sensing of coccolithophore blooms. Adv. Space Res. 1987, 7, 73-78. [CrossRef]

23. Duan, H.; Zhang, S.; Zhang, Y. Cyanobacteria bloom monitoring with remote sensing in Lake Taihu. J. Lake Sci. 2008, 20, 145-152. (In Chinese)

24. Ma, R.; Kong, F.; Duan, H.; Zhang, S.; Kong, W.; Hao, J. Spatiotemporal distribution of cyanobacterial scums based on satellite imageries in Lake Taihu, China. J. Lake Sci. 2008, 20, 687-694. (In Chinese)

25. Son, Y.B.; Min, J.E.; Ryu, J.H. Detecting massive green algae (Ulva prolifera) blooms in the Yellow Sea and East China Sea using geostationary ocean color imager (GOCI) data. Ocean Sci. J. 2012, 47, 359-375. [CrossRef]

26. Stumpf, R.P.; Tomlinson, M.C. Remote sensing of harmful algal blooms. Remote Sens. Coast. Aquat. Environ. 2005, 7, 277-296.

27. Holligan, P.M.; Viollier, M.; Harbour, D.S.; Camus, P.; Philippe, M.C. Satellite and ship studies of coccolithophore production along a continental shelf edge. Nature 1983, 304, 339-342. [CrossRef]

28. Gitelson, A.; Karnieli, A.; Goldman, N.; Yacobi, Y.Z.; Mayo, M. Chlorophyll estimation in the southeastern Mediterranean using CZCS images: Adaption of an algorithm and its validation. J. Mar. Syst. 1996, 9, 283-290. [CrossRef]

29. Kopelevich, O.V.; Sheberstov, S.V.; Yunev, O.; Basturk, O.; Finenko, Z.Z.; Nikonov, S.; Vedernikov, V.I. Surface chlorophyll in the Black Sea over 1978-1986 derived from satellite and in situ data. J. Mar. Syst. 2002, 36, 145-160. [CrossRef]

30. Gower, J.F.R. Red tide monitoring using AVHRR HRPT imagery from a local receiver. Remote Sens. Environ. 1994, 48, 309-318. [CrossRef]

31. Kahru, M.; Mitchell, B.G.; Diaz, A.; Miura, M. MODIS detects a devastating algal bloom in Paracas Bay, Peru. EOS Trans. Am. Geophys. Union 2004, 85, 465-472. [CrossRef]

32. Rouse, J.W.; Haas, R.H.; Schell, J.A.; Deering, D.W. Monitoring vegetation systems in the Great Plains with ERTS-1. In 3rd Earth Resources Technology Satellite Symposium; NASA: Washington, DC, USA, 1973; pp. 309-317.

33. Hu, C.; He, M. Origin and offshore extent of floating algae in Olympic sailing area. EOS Trans. Am. Geophys. Union 2008, 89, 302-303. [CrossRef]

34. Garcia, R.A.; Fearns, P.; Keesing, J.K.; Liu, D. Quantification of floating macroalgae blooms using the scaled algae index. J. Geophys. Res. Oceans 2013, 118, 26-42. [CrossRef]

35. Prangsma, G.J.; Roozekrans, J.N. Using NOAA AVHRR imagery in assessing water quality parameters. Int. J. Remote Sens. 1989, 10, 811-818. [CrossRef] 
36. Huete, A.; Justice, C.; Leeuwen, W.V. MODIS Vegetation Index (MOD13) Algorithm Theoretical Basis Document (Ver 3.0); NASA: Washington, DC, USA, 1999.

37. Wynne, T.T.; Stumpf, R.P.; Tomlinson, M.C.; Dybleb, J. Characterizing a cyanobacterial bloom in western Lake Erie using satellite imagery and meteorological data. Limnol. Oceanogr. 2010, 55, 2025-2036. [CrossRef]

38. Gower, J.F.R.; Doerffer, R.; Borstad, G.A. Interpretation of the $685 \mathrm{~nm}$ peak in water-leaving radiance spectra in terms of fluorescence, absorption and scattering, and its observation by MERIS. Int. J. Remote Sens. 1999, 20, 1771-1786. [CrossRef]

39. Gower, J.; King, S.; Borstad, G.; Brown, L. Detection of intense plankton blooms using the $709 \mathrm{~nm}$ band of the MERIS imaging spectrometer. Int. J. Remote Sens. 2005, 26, 2005-2012. [CrossRef]

40. Wynne, T.T.; Stumpf, R.P.; Tomlinson, M.C.; Warner, R.A.; Tester, P.A.; Dyble, J.; Fahnenstiel, G.L. Relating spectral shape to cyanobacterial scums in the Laurentian Great Lakes. Int. J. Remote Sens. 2008, 29, 3665-3672. [CrossRef]

41. Wynne, T.T.; Stumpf, R.P.; Briggs, T.O. Comparing MODIS and MERIS spectral shapes for cyanobacterial bloom detection. Int. J. Remote Sens. 2013, 34, 6668-6678. [CrossRef]

42. Wynne, T.T.; Stumpf, R.P.; Tomlinson, M.C.; Fahnenstiel, G.L.; Dyble, J.; Schwab, D.J.; Joshi, S.J. Evolution of a cyanobacterial bloom forecast system in western lake Erie: Development and initial evaluation. J. Great Lakes Res. 2013, 39, 90-99. [CrossRef]

43. Stumpf, R.P.; Wynne, T.T.; Baker, D.B.; Fahnenstiel, G.L. Interannual variability of cyanobacterial scums in lake Erie. PLoS ONE 2012, 7. [CrossRef] [PubMed]

44. Matthews, M.W.; Bernard, S.; Robertson, L. An algorithm for detecting trophic status (chlorophyll-a), cyanobacterial-dominance, surface scums and floating vegetation in inland and coastal waters. Remote Sens. Environ. 2012, 124, 637-652. [CrossRef]

45. Matthews, M.W.; Odermatt, D. Improved algorithm for routine monitoring of cyanobacteria and eutrophication in inland and near-coastal waters. Remote Sens. Environ. 2015, 156, 374-382. [CrossRef]

46. Hu, C. A novel ocean color index to detect floating algae in the global oceans. Remote Sens. Environ. 2009, 113, 2118-2129. [CrossRef]

47. Hu, C.H.; Lee, Z.L.; Ma, R.M.; Yu, K.; Li, D. Moderate resolution imaging spectroradiometer (MODIS) observations of cyanobacteria blooms in Taihu Lake, China. J. Geophys. Res. 2010, 115. [CrossRef]

48. Hu, C.; Cannizzaro, J.; Carder, K.L.; Karger, F.E.M.; Hardya, R. Remote detection of Trichodesmium blooms in optically complex coastal waters: Examples with MODIS full-spectral data. Remote Sens. Environ. 2010, 114, 2048-2058. [CrossRef]

49. Huang, C.; Li, Y.; Yang, H.; Sun, D.; Yu, Z.; Zhang, Z.; Chen, X.; Xu, L. Detection of algal bloom and factors influencing its formation in Taihu lake from 2000 to 2011 by MODIS. Environ. Earth Sci. 2014, 71, 3705-3714. [CrossRef]

50. Zhang, Y.; Ma, R.; Zhang, M.; Duan, H.; Loiselle, S.; Xu, J. Fourteen-year record (2000-2013) of the spatial and temporal dynamics of floating algae blooms in lake Chaohu, observed from time series of MODIS images. Remote Sens. 2015, 7, 10523-10542. [CrossRef]

51. Alem, A.E.; Chokmani, K.; Laurion, I.; Adlouni, S.E. An adaptive model to monitor chlorophyll-a in inland waters in southern Quebec using downscaled MODIS imagery. Remote Sens. 2014, 6, 6446-6471. [CrossRef]

52. Work, E.A.; Gilmer, D.S. Utilization of satellite data for inventorying prairie ponds and potholes. Photogramm. Eng. Remote Sens. 1976, 42, 685-694.

53. Kempka, R.G.; Kollasch, R.P.; Koeln, G.T. Ducks unlimited: Using GIS to preserve the pacific flyway's wetland resource. GIS World 1992, 5, 46-52.

54. Jakubauskas, M.; Kindscher, K.; Debinski, D. Multitemporal characterization and mapping of montane sagebrush communities using Indian IRS LISS-II imagery. Geocarto Int. 1998, 13, 65-74. [CrossRef]

55. Macleod, R.D.; Congalton, R.G. A quantitative comparison of change-detection algorithms for monitoring eelgrass from remotely sensed data. Photogramm. Eng. Remote Sens. 1998, 64, 207-216.

56. Gullström, M.; Lundén, B.; Bodin, M.; Kangwe, J.; Öhman, M.C.; Mtolera, M.S.P.; Björk, M. Assessment of changes in the seagrass-dominated submerged vegetation of tropical Chwaka bay (Zanzibar) using satellite remote sensing. Estuar. Coast. Shelf Sci. 2006, 67, 399-408. [CrossRef]

57. Dogan, O.K.; Akyurek, Z.; Beklioglu, M. Identification and mapping of submerged plants in a shallow lake using Quickbird satellite data. J. Environ. Manag. 2009, 90, 2138-2143. [CrossRef] [PubMed] 
58. Hewitt, M.J. Synoptic inventory of riparian ecosystems: The utility of Landsat thematic mapper data. For. Ecol. Manag. 1990, 33-34, 605-620. [CrossRef]

59. MacAlister, C.; Mahaxay, M. Mapping wetlands in the lower Mekong Basin for wetland resource and conservation management using Landsat ETM images and field survey data. J. Environ. Manag. 2009, 90, 2130-2137. [CrossRef] [PubMed]

60. De Colstoun, E.B. National park vegetation mapping using multitemporal Landsat 7 data and a decision tree classifier. Remote Sens. Environ. 2003, 85, 316-327. [CrossRef]

61. Baker, C.; Lawrence, R.; Montagne, C.; Patten, D. Mapping wetlands and riparian areas using Landsat ETM+ imagery and decision-tree-based models. Wetlands 2006, 26, 465-474. [CrossRef]

62. Wright, C.; Gallant, A. Improved wetland remote sensing in Yellowstone national park using classification trees to combine tm imagery and ancillary environmental data. Remote Sens. Environ. 2007, 107, 582-605. [CrossRef]

63. Davranche, A.; Lefebvre, G.; Poulin, B. Wetland monitoring using classification trees and SPOT-5 seasonal time series. Remote Sens. Environ. 2010, 114, 552-562. [CrossRef]

64. Zhao, D.; Jiang, H.; Yang, T.; Cai, Y.; Xu, D.; An, S. Remote sensing of aquatic vegetation distribution in Taihu lake using an improved classification tree with modified thresholds. J. Environ. Manag. 2012, 95, 98-107. [CrossRef] [PubMed]

65. Zhao, D.; Lv, M.; Jiang, H.; Cai, Y.; Xu, D.; An, S. Spatio-temporal variability of aquatic vegetation in Taihu lake over the past 30 years. PLoS ONE 2013, 8. [CrossRef] [PubMed]

66. Luo, J.; Ma, R.; Duan, H.; Hu, W.; Zhu, J.; Huang, W.; Lin, C. A new method for modifying thresholds in the classification of tree models for mapping aquatic vegetation in Taihu Lake with satellite images. Remote Sens. 2014, 6, 7442-7462. [CrossRef]

67. Oyama, Y.; Matsushita, B.; Fukushima, T. Distinguishing surface cyanobacterial scums and aquatic macrophytes using Landsat/TM and ETM+ shortwave infrared bands. Remote Sens. Environ. 2015, 157, 35-47. [CrossRef]

68. Liu, X.; Zhang, Y.; Shi, K.; Zhou, Y.; Tang, X.; Zhu, G.; Qin, B. Mapping aquatic vegetation in a large, shallow eutrophic lake: A frequency-based approach using multiple years of MODIS data. Remote Sens. 2015, 7, 10295-10320. [CrossRef]

69. Zhang, Y.; Liu, X.; Qin, B.; Shi, K.; Deng, J.; Zhou, Y. Aquatic vegetation in response to increased eutrophication and degraded light climate in eastern lake Taihu: Implications for lake ecological restoration. Sci. Rep. 2016, 6. [CrossRef] [PubMed]

70. Gao, B.C. NDWI-A normalized difference water index for remote sensing of vegetation liquid water from space. Remote Sens. Environ. 1996, 58, 257-266. [CrossRef]

71. Rogers, A.; Kearney, M. Reducing signature variability in unmixing coastal marsh thematic mapper scenes using spectral indices. Int. J. Remote Sens. 2004, 25, 2317-2335. [CrossRef]

72. Qi, L.; Hu, C.; Duan, H.; Cannizzaro, J.; Ma, R. A novel meris algorithm to derive cyanobacterial phycocyanin pigment concentrations in a eutrophic lake: Theoretical basis and practical considerations. Remote Sens. Environ. 2014, 154, 298-317. [CrossRef]

73. Qi, L.; Hu, C.; Duan, H.; Barnes, B.; Ma, R. An EOF-based algorithm to estimate chlorophyll a concentrations in Taihu Lake from MODIS land-band measurements: Implications for near real-time applications and forecasting models. Remote Sens. 2014, 6, 10694-10715. [CrossRef]

74. Palmer, S.C.J.; Hunter, P.D.; Lankester, T.; Hubbard, S.; Spyrakos, E.; Tyler, A.N.; Présing, M.; Horváth, H.; Lamb, A.; Balzter, H.; et al. Validation of ENVISAT Meris algorithms for chlorophyll retrieval in a large, turbid and optically-complex shallow lake. Remote Sens. Environ. 2015, 157, 158-169. [CrossRef]

75. Hu, C.; Chen, Z.; Clayton, T.D.; Swarzenski, P.; Brock, J.C.; Muller-Karger, F.E. Assessment of estuarine water-quality indicators using MODIS medium-resolution bands: Initial results from Tampa bay, FL. Remote Sens. Environ. 2004, 93, 423-441. [CrossRef]

76. Le, C.; Hu, C.; English, D.; Cannizzaro, J.; Chen, Z.; Feng, L.; Boler, R.; Kovach, C. Towards a long-term chlorophyll-a data record in a turbid estuary using MODIS observations. Prog. Oceanogr. 2013, 109, 90-103. [CrossRef]

77. Qin, B.Q.; Hu, W.P.; Chen, W.M. Process and Mechanism of Environmental Changes of the Taihu Lake; Science Press: Beijing, China, 2004. 
78. Qin, B.; Xu, P.; Wu, Q.; Luo, L.; Zhang, Y. Environmental issues of lake Taihu, China. Hydrobiologia 2007, 581, 3-14. [CrossRef]

79. Ma, R.; Duan, H.; Gu, X.; Zhang, S. Detecting aquatic vegetation changes in Taihu lake, China using multi-temporal satellite imagery. Sensors 2008, 8, 3988-4005. [CrossRef] [PubMed]

80. Kalff, J. Limnology: Inland Water Ecosystems; Prentice Hall: Upper Saddle River, NJ, USA, 2002.

81. Lei, Z. Study on Aquatic Macrophyte Vegetations and Their Environment Effects in Taihu Lake. Ph.D. Thesis, Jinan University, Jinan, China, 2006.

82. Mueller, J.L.; Fargion, G.S.; McClain, C.R. Ocean Optics Protocols for Satellite Ocean Color Sensor Validation, Revision 4. Volume VI: Special Topics in Ocean Optics Protocols and Appendices; NASA Goddard Space Flight Center: Greenbelt, MD, USA, 2003.

83. Mobley, C.D. Estimation of the remote-sensing reflectance from above-surface measurements. Appl. Opt. 1999, 38, 7442-7455. [CrossRef] [PubMed]

84. Ahn, Y.H.; Shanmugam, P. Detecting the red tide algal blooms from satellite ocean color observations in optically complex Northeast-Asia coastal waters. Remote Sens. Environ. 2006, 103, 419-437. [CrossRef]

85. Dev, P.J.; Shanmugam, P. A new theory and its application to remove the effect of surface-reflected light in above-surface radiance data from clear and turbid waters. J. Quant. Spectrosc. Radiat. Transf. 2014, 142, 75-92. [CrossRef]

86. Sun, D.; Hu, C.; Qiu, Z.; Shi, K. Estimating phycocyanin pigment concentration in productive inland waters using Landsat measurements: A case study in lake Dianchi. Opt. Exp. 2015, 23, 3055-3074. [CrossRef] [PubMed]

87. NASA's OceanColor Web. Available online: http:/ / oceancolor.gsfc.nasa.gov (accessed on 16 December 2016).

88. Gordon, H.R.; Clark, D.K. Clear water radiances for atmospheric correction of coastal zone color scanner imagery. Appl. Opt. 1981, 20, 4175-4180. [CrossRef] [PubMed]

89. Ruddick, K.G.; Ovidio, F.; Rijkeboer, M. Atmospheric correction of SeaWIFS imagery for turbid coastal and inland waters. Appl. Opt. 2000, 39, 897-912. [CrossRef] [PubMed]

90. Wang, M.; Shi, W. The NIR-SWIR combined atmospheric correction approach for MODIS ocean color data processing. Opt. Exp. 2007, 15, 15722-15733. [CrossRef]

91. Bailey, S.W.; Franz, B.A.; Werdell, P.J. Estimation of near-infrared water-leaving reflectance for satellite ocean color data processing. Opt. Express 2010, 18, 7521-7527. [CrossRef] [PubMed]

92. Reinart, A.; Herlevi, A.; Arst, H.; Sipelgas, L. Preliminary optical classification of lakes and coastal waters in Estonia and South Finland. J. Sea Res. 2003, 49, 357-366. [CrossRef]

93. Gitelson, A.A.; Dall'Olmo, G.; Moses, W.M.; Rundquist, D.C.; Barrow, T.; Fisher, T.R.; Gurlin, D.; Holz, J. A simple semi-analytical model for remote estimation of chlorophyll-a in turbidwaters: Validation. Remote Sens. Environ. 2008, 112, 3582-3593. [CrossRef]

94. Bricaud, A.; Roesler, C.; Zaneveld, J.R.V. In situ methods for measuring the inherent optical properties of ocean waters. Limnol. Oceanogr. 1995, 40, 393-410. [CrossRef]

95. Dekker, A.G.; Malthus, T.J.; Goddijn, L.M. Monitoring cyanobacteria in eutrophic waters using airborne imaging spectroscopy and multispectral remote sensing systems. In Proceedings of the 6th Australasian Remote Sensing Conference, Wellington, NZ, USA, 2-6 November 1992; pp. 204-214.

96. Le, C.; Li, Y.; Zha, Y.; Sun, D.; Huang, C.; Lu, H. A four-band semi-analytical model for estimating chlorophyll a in highly turbid lakes: The case of Taihu Lake, China. Remote Sens. Environ. 2009, 113, 1175-1182. [CrossRef]

97. Hoffer, R.M. Biological and physical considerations in applying computer-aided analysis techniques to remote sensor data. In Remote Sensing: The Quantitative Approach; Swain, P.H., Davis, S.M., Eds.; McGraw-Hill: New York, NY, USA, 1978; pp. 227-289.

98. Feng, L.; Hu, C.; Chen, X.; Cai, X.; Tian, L.; Chen, L. Human induced turbidity changes in Poyang Lake between 2000 and 2010: Observations from MODIS. J. Geophys. Res. 2012, 117. [CrossRef]

99. Foody, G.M. Local characterization of thematic classification accuracy through spatially constrained confusion matrices. Int. J. Remote Sens. 2005, 26, 1217-1228. [CrossRef]

100. Congalton, R.G. A review of assessing the accuracy of classifications of remotely sensed data. Remote Sens. Environ. 1991, 37, 35-46. [CrossRef]

101. New Hampshire View Web. Available online: http://www.nhview.unh.edu/accuracyprograms.html (accessed on 16 December 2016). 
102. Wang, M.; Shi, W. Cloud masking for ocean color data processing in the coastal regions. IEEE Trans. Geosci. Remote Sens. 2006, 44, 3196-3205. [CrossRef]

103. Ma, R.; Duan, H.; Liu, Q.; Loiselle, S.A. Approximate bottom contribution to remote sensing reflectance in Taihu Lake, China. J. Great Lakes Res. 2011, 37, 18-25. [CrossRef]

104. Duan, H.; Ma, R.; Loiselle, S.A.; Shen, Q.; Yin, H.; Zhang, Y. Optical characterization of black water blooms in eutrophic waters. Sci. Total Environ. 2014, 482-483, 174-183. [CrossRef] [PubMed]

105. Zhao, J.; Hu, C.; Lapointe, B.; Melo, N.; Johns, E.; Smith, R. Satellite-observed black water events off southwest florida: Implications for coral reef health in the Florida keys national marine sanctuary. Remote Sens. 2013, 5, 415-431. [CrossRef]

106. Yang, M.; Yu, J.W.; Li, Z.L.; Guo, Z.H.; Burch, M.; Lin, T.F. Taihu lake not to blame for Wuxi's woes. Science 2008, 319. [CrossRef] [PubMed]

107. Lu, G.; Ma, Q.; Zhang, J. Analysis of black water aggregation in Taihu Lake. Water Sci. Eng. 2011, 4, 374-385.

108. Lei, Z.; Bing, Z.; Junsheng, L.; Qian, S.; Fangfang, Z.; Ganlin, W. A study on retrieval algorithm of black water aggregation in Taihu Lake based on HJ-1 satellite images. In IOP Conference Series: Earth and Environmental Science; IOP Publishing: Bristol, UK, 2014.

109. Mi, W.J.; Zhu, D.W.; Zhou, Y.Y.; Zhou, H.D.; Yang, T.W.; Hamilton, D.P. Influence of Potamogeton crispus growth on nutrients in the sediment and water of lake Tangxunhu. Hydrobiologia 2007, 603, 139-146. [CrossRef]

110. Antoine, D.; Morel, A. Relative importance of multiple scattering by air molecules and aerosols in forming the atmospheric path radiance in the visible and near-infrared parts of the spectrum. Appl. Opt. 1998, 37, 2245-2259. [CrossRef] [PubMed]

111. Zhao, D.; Jiang, H.; Cai, Y.; An, S. Artificial regulation of water level and its effect on aquatic macrophyte distribution in Taihu lake. PLoS ONE 2012, 7. [CrossRef] [PubMed]

(C) 2017 by the authors; licensee MDPI, Basel, Switzerland. This article is an open access article distributed under the terms and conditions of the Creative Commons Attribution (CC BY) license (http:/ / creativecommons.org/licenses/by/4.0/). 